\title{
A Global View of Coastal Low-Level Wind Jets Using an Ensemble of Reanalyses ${ }^{\mathscr{A}}$
}

\author{
Daniela C. A. Lima And Pedro M. M. SoAReS \\ Instituto Dom Luiz, Faculty of Sciences, University of Lisbon, Lisbon, Portugal \\ Alvaro SEMEDo \\ Department of Water Science and Engineering, International Institute for Hydraulic and Environmental Engineering Delft \\ Institute for Water Education, Delft, Netherlands, and Instituto Dom Luiz, Faculty of Sciences, University of Lisbon, \\ Lisbon, Portugal \\ RITA M. CARDOSO \\ Instituto Dom Luiz, Faculty of Sciences, University of Lisbon, Lisbon, Portugal
}

(Manuscript received 15 June 2017, in final form 3 November 2017)

\begin{abstract}
Global reanalyses are powerful tools to study the recent climate. They are built by combining forecast models with observations through data assimilation, which provide complete spatial and temporal information of observable and unobservable parameters. The reanalyses constitute very valuable threedimensional data of the atmosphere, which make it possible to investigate a panoply of atmospheric processes, such as coastal low-level jets (CLLJs). In the present study, three global reanalyses, the European Centre for Medium-Range Weather Forecasts (ECMWF) interim reanalysis (ERA-Interim), the Japanese 55-year Reanalysis (JRA-55), and the Modern-Era Retrospective Analysis for Research and Applications, version 2 (MERRA-2), are used to build an ensemble of reanalyses for a period encompassing 1980-2016 with 6-hourly output. A detailed global climatology of CLLJs is presented based on this ensemble of reanalyses. This reanalysis ensemble makes it possible to explore the ability of reanalysis to represent the CLLJs mitigating its uncertainty and adding robustness. The annual and diurnal cycle as well as the interannual variability are analyzed in order to evaluate the temporal variability of frequency of occurrence of CLLJ. The ensemble mean displays a good representation of the seasonal spatial variability of frequency of occurrence of coastal jets. The Oman and Benguela CLLJs show, respectively, a decrease and increase of frequency of occurrence in the studied period, which are statistically significant during boreal summer and austral spring. The coastal jets have higher mean frequencies of occurrences during late afternoon and early evening. During the season where each CLLJ has higher mean frequency of occurrence, the Oman CLLJ is the most intense and occurs at higher altitudes.
\end{abstract}

\section{Introduction}

Eastern boundary upwelling systems are among the most productive ocean ecosystems in the Atlantic and Pacific basins. The eastern boundary upwelling systems represent only $\sim 2 \%$ of the global ocean surface area but contribute more than $20 \%$ of marine fisheries and are essential habitats for marine biodiversity

Supplemental information related to this paper is available at the Journals Online website: https://doi.org/10.1175/JCLI-D-170395.s1.

Corresponding author: Daniela C.A. Lima, dclima@fc.ul.pt
(Sydeman et al. 2014; Wang et al. 2015). Coastal processes, such as marine boundary layer clouds (Nuss et al. 2000), upwelling (Pauly and Christensen 1995), and coastal low-level jets (Winant et al. 1988; Warner 2004), play an important role in defining the regional climate in the midlatitude and subtropical western continental coastal areas.

The regional climates of the midlatitude and subtropical western coastal regions are strongly modulated by coast-parallel winds. Because of the effect of upwelling currents along these coasts, there is a reduction in sea surface temperature (SST), which further leads to a decrease in the evaporation over the ocean and consequently to a low water vapor content in the lower 
marine atmosphere. Similarly, over land, the water vapor content in the air decreases because of the strong coastal-parallel winds, which reduce the cross-coast advection of marine air inshore. For these reasons, some of the western continental areas, such as the Atacama (South America) and Namib (South Africa) Deserts, are dry and arid regions (Warner 2004, p. 48). In particular, these two deserts have similar features that contribute to the extreme aridity. The Atacama and Namib Deserts are located between tropical and midlatitude weather. During summer, rain prevails in the north because of the summer convective rainfall, and during winter, rain is predominant in the south because of the winter cyclone precipitation. Also, because of the higher elevations of the mountains that limit these deserts eastward, there is a higher variability in the mean temperature. The cloud formation along the coastal jet areas is related to the dynamics of the marine atmospheric boundary layer (MABL) and is often dominated by the presence of stratocumulus decks.

Coastal low-level jets (CLLJs) occur along the eastern flank of the semipermanent subtropical midlatitude high pressure systems (Winant et al. 1988; Ranjha et al. 2013), with one exception in the Arabian Sea (Ranjha et al. 2015). The high pressure systems over the ocean and continental thermal lows, developed because of the intense heating inland, are the key elements for the synoptic forcing of along-coast-parallel winds. Coastal jets occur mainly during summer, but the associated synoptic pattern starts to develop during late spring and can last up to early autumn. The CLLJ regions are found along the cold equatorward eastern boundary current systems: the California Current [California CLLJ (CCJ); Burk and Thompson 1996; Parish 2000; Winant et al. 1988) and the Canary Current, (Iberian Peninsula and North African CLLJs (NACJs); Soares et al. 2014) in the Northern Hemisphere (NH) and the Humboldt Current [Peru-Chile CLLJ (PCCJ); Garreaud and Muñoz 2005; Muñoz and Garreaud 2005], the Benguela Current [Benguela CLLJ (BCJ); Nicholson 2010], and the Western Australian Current [Western Australian CLLJ (WACJ); Stensrud 1996), in the Southern Hemisphere (SH). The Oman CLLJ (OCJ; Ranjha et al. 2015), located along the southeast Arabian Peninsula coast in the Arabian Sea, is an exception to this pattern, since it develops within the South Asia monsoon, forcing a coastal-parallel flow along Yemen and Oman.

Although coastal jets have an associated synoptic forcing, they are a mesoscale phenomenon. In the CLLJ regions, coast-parallel winds over the ocean generate upwelling currents because of offshore Ekman transport (Haack et al. 2005; Vallis 2012). This brings deep cold water to the surface, sharpening the temperature and pressure gradients near the coast and leading to a local increase of the wind speed and to a decrease of the SST (Chao 1985). Sharp thermal and pressure gradients build at the coast, giving rise to strong baroclinic structures (Burk and Thompson 1996; Rijo et al. 2018).

The high pressure subsidence of warm air over the MABL and the cold air close to the surface generate a strong capping temperature inversion (Beardsley et al. 1987). The temperature of the MABL decreases closer to the coast because of the low SST, resulting in a sloping inversion toward the coast. This inversion slopes onshore, implying a maximum horizontal temperature gradient at the inversion, which generates an increase in baroclinicity and an increase in the SST toward offshore. This results in a thermal wind structure associated to the CLLJ occurrences, which increases the jet wind speed, with the maximum occurring in the first $1000 \mathrm{~m}$ from the sea level (Beardsley et al. 1987; Garreaud and Muñoz 2005; Soares et al. 2014; Ranjha et al. 2013, 2015). The CLLJ wind speed is stronger in altitude because of the surface friction that decreases the airflow at the surface. The MABL is therefore cool (low SST), moist, and well mixed (because of the vertical wind shear that mechanically produces turbulent mixing). Although the height of the coastal jets is relatively low, their horizontal extent can exceed distances on the order of hundreds of kilometers, limited by the Rossby radius of deformation (Winant et al. 1988; Muñoz and Garreaud 2005; Ranjha et al. 2013, 2015).

Because of the interaction with coastal mountains, capes, and headlands, the wind speed may be enhanced locally and change direction (Chao 1985). When coastal mountains are higher than the capping inversion of the MABL, the lateral component of the wind speed is blocked, and the flow becomes semigeostrophic (Overland 1984; Tjernström 1999). When this happens, the wind speed is intensified at the coast (Winant et al. 1988; Burk and Thompson 1996; Tjernström and Grisogono 2000). When the interaction between the coastal-parallel flow and capes or headlands occurs, gravity waves might be excited and, in some cases, can also propagate along the MABL capping inversion. The flow is adjusted because of the gravity waves, which leads to changes in wind speed and direction in the lee of the capes. When the phase speed of the gravity waves is lower (higher) than the wind speed, the flow becomes supercritical (subcritical). If the flow is supercritical, the wind speed may also be intensified downstream of capes and headlands through a process called expansion fan. Because of expansion fan, the direction of the wind speed changes toward the coast, and the MABL height decreases, and an increase of the wind speed in the lee of the capes through a Bernoulli effect occurs (Winant 
et al. 1988). Because of the expansion fan, the increase of the wind speed leads to an impact on the local SST, through the enhancement of the upwelling, and cloud cover in the lee of the capes and headlands.

The first CLLJs studies focused mainly on the California and the Peru-Chile coastal jets and were based on field campaigns (e.g., Beardsley et al. 1987; Winant et al. 1988) and, later, on modeling and theoretical efforts (e.g., Burk and Thompson 1996; Garreaud and Muñoz 2005; Ranjha et al. 2016). These studies, nevertheless, did not address a climatological view of coastal jets despite the awareness raised by Winant et al. (1988, their Fig. 14). Recently, Ranjha et al. (2013) presented the first global climatology of CLLJ regions based on the European Centre for Medium-Range Weather Forecasts (ECMWF) interim reanalysis (ERA-Interim), at $1^{\circ}$ resolution. Their study was centered on a filtering algorithm that allowed the detection of CLLJ based on the analysis of the vertical wind speed and temperature profiles. The global pattern of CLLJ occurrences along the eastern boundary upwelling system areas and in the Arabian Sea proposed by Ranjha et al. (2013) was in agreement with the potential areas mentioned by Winant et al. (1988). Although Winant et al. (1988) did not consider the existence of the Iberian Peninsula CLLJ (IPCJ), Ranjha et al. (2013) suggested the existence of two coastal jets along the Portugal-Canary current separated by the Gulf of Cadiz, the Iberian Peninsula, and North Africa CLLJ.

The study of the global CLLJ systems, simultaneously in the seven areas of occurrence, is only possible using modeling data, preferably hindcast or reanalysis, the latter having higher resolution and increasing observational data assimilated, allowing a three-dimensional inspection of wind and temperature. A reanalysis dataset consists of a climate or weather model simulation of the past (Bengtsson et al. 2007). These products are generated using numerical weather prediction systems, assimilating different types of observations, and provide a uniform dataset in time and space. Reanalysis products are an important resource for research of atmospheric phenomena. However, the availability (in both time and space) and the quality of the assimilated data may limit the improvements and quality of reanalysis products.

In the last years, different reanalysis products have been used in different concepts. A number of scientific studies have been carried out to evaluate the uncertainties in variables of the reanalysis products but also their quality. Hodges et al. (2011) carried out a comparison of synoptic-scale extratropical cyclones in both hemispheres in recent reanalyses and showed that there is a good agreement between them. Bosilovich et al. (2008) evaluated the performance of ERA-40, Japanese 25-year Reanalysis Project (JRA-25), National Centers for Environmental Prediction (NCEP)-1 and NCEP-2 against Global Precipitation Climatology. The southern African precipitation was evaluated by Zhang et al. (2013) based on seasonal cycle of eight reanalyses [ERA-40, ERA-Interim, JRA-25, Modern-Era Retrospective Analysis for Research and Applications (MERRA), NCEP Climate Forecast System Reanalysis (CFSR), NCEP-1, NCEP-2, and Twentieth Century Reanalysis, version 2 (20CRv2)] and concluded that the CFSR and 20CRv2 yielded better results. Moalafhi et al. (2016) performed an evaluation to determine which reanalysis (ERA-Interim, NCEP-1, NCEP-2, MERRA, and 20CRv2) could provide the most accurate lateral boundary conditions for regional modeling over southern Africa. This study reveals that when compared to 20CRv2, MERRA and ERA-Interim were preferable for use in downscaling in this region.

Currently, four global reanalysis products are freely available: ERA-Interim (Dee et al. 2011); Japanese 55-year Reanalysis (JRA-55; Kobayashi et al. 2015); MERRA, version 2 (MERRA-2; Bosilovich et al. 2015); and CFSR (Saha et al. 2010). Here, we propose the assessment of the ability of these four global reanalyses to represent the main CLLJ features. Second, a thorough detailed global climatology of CLLJ is presented based on a reanalysis ensemble. The intra-annual variability and the coastal jet diurnal cycle is also investigated.

The remainder of the paper is organized as follows: In section 2, the reanalyses data and analyses methodologies are described. Section 3 presents the comparison of CLLJs results between reanalysis products. The global CLLJs climatology and their variability are presented in section 4, and conclusions are summarized in section 5 .

\section{Data and methodology}

\section{a. Reanalyses}

A reanalysis can be defined as a rerun of the past using as much observations as possible, with the goal of overcoming inhomogeneities due to the model and the data assimilation scheme. The best available model and data assimilation scheme, now unchanged during the production of the reanalysis, are used to repeat the analysis procedure. Despite this, inhomogeneities may arise because of uneven data coverage as well as because of changes in observation systems (Sterl 2004). The 6-hourly ERA-Interim, JRA-55, MERRA-2, and CFSR results are used here. The summarized details of the reanalyses can be seen in Table 1 .

The ERA-Interim is the newest ECMWF reanalysis product, starting in 1979 and being updated almost in 
TABLE 1. Summary details of global climate reanalyses used in this study.

\begin{tabular}{|c|c|c|c|c|c|c|c|}
\hline Name & Organization & Temporal coverage & $\begin{array}{l}\text { Horizontal } \\
\text { resolution }\end{array}$ & $\begin{array}{l}\text { Vertical } \\
\text { levels }\end{array}$ & $\begin{array}{c}\text { SST and } \\
\text { sea ice forcing }\end{array}$ & Assimilation & References \\
\hline ERA-Interim & ECMWF & 1979-present & $\mathrm{T} 255$ & 60 & $\begin{array}{l}\text { Daily OISST } \\
\quad \text { (from 2002) }\end{array}$ & 4DVAR & Dee et al. (2011) \\
\hline JRA-55 & JMA & 1958-present & T319 & 60 & COBE-SST & 4DVAR & $\begin{array}{l}\text { Kobayashi et al. } \\
\text { (2015) }\end{array}$ \\
\hline MERRA-2 & NASA GMAO & 1980-present & $0.625^{\circ} \times 0.5^{\circ}$ & 72 & $\begin{array}{l}\text { Daily OISST } \\
\quad \text { (from 2002) }\end{array}$ & 3DVAR & $\begin{array}{l}\text { Bosilovich et al. } \\
\text { (2015) }\end{array}$ \\
\hline CFSR & NCEP & 1979-2010 & $0.5^{\circ} \times 0.5^{\circ}$ & 37 & $\begin{array}{l}\text { Coupled ocean-sea } \\
\text { ice model }\end{array}$ & 3DVAR & Saha et al. (2010) \\
\hline
\end{tabular}

real time (Dee et al. 2011). ERA-Interim was generated by the ECMWF Integrated Forecast System, version cycle $31 \mathrm{r} 2$, which is a two-way coupled atmospherewave model system (Janssen 2004). The atmospheric fields have a horizontal resolution of approximately $79 \mathrm{~km}$ (T255 spectral) on a reduced Gaussian grid with 60 vertical model levels up to $0.1 \mathrm{hPa}$. A fourdimensional variational (4DVAR) data assimilation scheme was used every $12 \mathrm{~h}$ (Courtier et al. 1994) for atmospheric and wave observation analyses. The boundary conditions for SST and sea ice concentration (SIC) were derived from different sources. Prior to 2002, the NCEP two-dimensional variational (2DVAR) sea surface temperature (1989-June 2001) and NOAA Optimum Interpolation Sea Surface Temperature, version 2 (OISSTv2; July-December 2001), were used. Between 2002 and January 2009, ERA-Interim used the daily NCEP real-time global sea surface temperature. From 2009 onward, the Operational Sea Surface Temperature and Sea Ice Analysis (OSTIA; Donlon et al. 2012) is used as SST and sea ice forcing.

The JRA-55 covers the period from 1958 to the present. JRA-55 was produced with the TL319 spectral resolution $(\sim 55-\mathrm{km}$ horizontal resolution) version of the Japan Meteorological Agency global spectral model in reduced Gaussian grid with 60 levels up to $0.1 \mathrm{hPa}$ (Kobayashi et al. 2015). The atmospheric analysis is based on incremental 4DVAR assimilation scheme (Courtier et al. 1994) every $6 \mathrm{~h}$. The SST and sea ice forcing used in JRA-55 is the Centennial In Situ Observation-Based Estimates of the Variability of SSTs and Marine Meteorological Variables (COBE-SST; Ishii et al. 2005).

The MERRA-2 is a second version of MERRA, where the atmospheric model and data assimilation system were improved (Bosilovich et al. 2015). MERRA-2 reanalysis spans from 1980 to the present. The atmospheric model used is version 5 of the Goddard Earth Observing System, with a horizontal resolution of $0.5^{\circ} \times 0.625^{\circ}$ and 72 hybrid eta levels up to $0.01 \mathrm{hPa}$. The atmospheric analysis is computed using a three-dimensional variational
(3DVAR) algorithm based on the Gridpoint Statistical Interpolation analysis system (GSI) every $6 \mathrm{~h}$ (Wu et al. 2002; Kleist et al. 2009). The MERRA-2 uses three different data sources for SST and SIC. Between 1980 and 1982, the monthly SST and SIC were given by Taylor et al. (2000) product with a horizontal resolution of $1^{\circ}$. From 1982 to 2006, MERRA-2 uses the daily Reynolds dataset with a horizontal resolution of $1 / 4^{\circ}$ (Reynolds et al. 2007). From 2006 onward, the daily and $1 / 20^{\circ}$ OSTIA dataset is used (Donlon et al. 2012).

The CFSR is the newest reanalysis from the NCEP and covers a 31-yr period from 1979 to 2010. The CFSR dataset uses the NCEP Climate Forecast System model and was generated by coupling the Global Forecast System (GFS) for the atmosphere and the ocean model (Saha et al. 2010). The horizontal resolution is T382 $(\sim 38 \mathrm{~km})$ with 64 hybrid vertical levels, with the top pressure $\sim 0.2 \mathrm{hPa}$. Although CFSR has 64 hybrid levels, this output is not available for download. For this reason, the 37 pressure levels available are used here. The atmospheric data assimilation is based on the GSI (Kleist et al. 2009) technique every $6 \mathrm{~h}$. The CFSR includes a coupled ocean model, the Geophysical Fluid Dynamics Laboratory Modular Ocean Model, version 4p0d (MOM4), and a two-layer sea ice model. The MOM4 is a finite-difference model with a zonal resolution of $\sim 1 / 2^{\circ}$ and 40 layers in the vertical. The SST analysis is performed by the optimal interpolation method on a spatial-grid resolution of $1 / 4^{\circ}$. The CFSR uses the Global Ocean Data Assimilation System for oceanic assimilation, which assimilates temperature and salinity observations every $6 \mathrm{~h}$.

\section{b. Methods}

The current study takes as reference the CLLJ detection method proposed by Ranjha et al. (2013), based on the analysis of the wind speed and temperature vertical profiles at each grid point. This CLLJ detection algorithm has been applied in different climate models in global (Semedo et al. 2016) and regional (Soares et al. 2014, 2017; Ranjha et al. 2015, 2016; Cardoso et al. 
2016; Rijo et al. 2018) CLLJ studies. The horizontal and vertical resolutions of global and regional climate models used in these studies differ between them, although with a successful detection of the coastal jet occurrences. Two regional studies, Iberian Peninsula and Oman CLLJ, were done with high horizontal resolution, at 9 (Soares et al. 2014) and $6 \mathrm{~km}$ (Ranjha et al. 2015), with 49 (20 within the boundary layer) and 51 (14 within the first $2 \mathrm{~km} \mathrm{MSL}$ ) vertical levels, respectively. Semedo et al. (2016) showed the impact of the end of the twentyfirst century projections on global CLLJs, using two ECEARTH runs, with a horizontal resolution of $125 \mathrm{~km}$ and 62 vertical levels ( 15 within the boundary layer).

In their global CLLJ climatology, Ranjha et al. (2013) state that false detections (false positives) can be obtained, in general, confined to regions where CLLJs are not supposed to be present (along the Antarctic ice cap or in continental areas, for example). To improve the CLLJ detection method proposed by Ranjha et al. (2013), sensitivity tests were performed. Several studies state that the wind speed maxima are found within the temperature inversion capping the MABL (e.g., Parish 2000; Bridger et al. 2005; Beardsley et al. 1987), while others mention that the jet core (wind speed maximum) resides at the top of the MABL (e.g., Burk and Thompson 1996; Garreaud and Muñoz 2005). The criterion in Ranjha et al. (2013) that forced the temperature at the jet maximum to be lower than that at two model levels above (inversion detection) does not consider a jet if it occurs at the top of MABL or at the level below the top. Therefore, this criterion has been reformulated. Through the analysis of the temperature vertical profile, the inversion layer of the MABL can be computed and its top identified. Furthermore, the vertical wind speed profile is analyzed in order to check if the wind speed maximum is in fact within the MABL temperature inversion or at the top. Considering this in the analysis of vertical profiles of temperature and wind speed, there is a slight increase in coastal jet detection in all areas. So the new criterion is defined as follows: "the jet maximum is within or at the top of the MABL temperature inversion" [replacing point 4 of the Ranjha et al. (2013) algorithm]. The revised algorithm identifies a CLLJ occurrence when the following criteria are met:

- The height of the jet maximum is within the lowest $1 \mathrm{~km}$ in the vertical.

- The wind speed at the jet maximum is at least $\sim 20 \%$ higher than the wind speed at the surface.

- The wind speed above the jet maximum decreases to below $\sim 80 \%$ of the wind speed at the surface (i.e., a $\sim 20 \%$ falloff) before reaching $5 \mathrm{~km}$ above its maximum.
- The jet maximum is within the MABL temperature inversion.

- The maximum temperature does not occur at the base (rejection of surface-based inversion).

This revised detection algorithm was applied to the 6-hourly reanalyses output. Different statistics of CLLJ, like frequency of occurrence, mean intensities, and jet height (wind speed maxima) were computed for each grid point of the CLLJs region (Fig. 1). The analysis was done for the 31-yr overlapping period of the four reanalyses (1980-2010). The seasonal spatial patterns of the coastal jets are compared between the four reanalysis products. Based on this assessment, an ensemble of reanalyses is then built. To describe the climatology and variability of CLLJs, two different methods were applied to compute the ensemble. For the mean spatial frequency of occurrence, the ensemble was calculated by averaging the seasonal frequencies of CLLJ occurrence with equal weights. Since the horizontal resolution is different in each reanalysis, the spatial distribution of CLLJ of individual datasets was interpolated into the lower-resolution grid. The interpolation method used is the first conservative remapping (Jones 1999). Histograms of frequency of occurrence and jet wind speeds were obtained in order to analyze the annual and diurnal cycle and interannual variability. The histograms are obtained by weighting the individual bins with equal weights:

$$
H(x)=\sum_{i=1}^{N} H(x)_{i} w g_{i}
$$

( $N=n^{\circ}$ of reanalyses), where $w g_{i}$ is the reanalysis weight.

The mean sea level pressure fields of different reanalyses were computed, with the zonal pressure gradient (PG) defined as

$$
\mathrm{PG}_{x}=-\frac{1}{\rho} \frac{\partial P}{\partial x}
$$

where $P$ is the mean sea level pressure. A constant air density $\rho$ was used with a value of $1.22 \mathrm{~kg} \mathrm{~m}^{-3}$. The same methodology used to compute the ensemble CLLJ mean of spatial frequency of occurrence was applied to the zonal PG.

\section{Coastal low-level jets climate in the different reanalyses}

In this section, the global coastal jets and global zonal PG climatologies, as represented by each of the four reanalyses, is described. The maps of the mean seasonal 


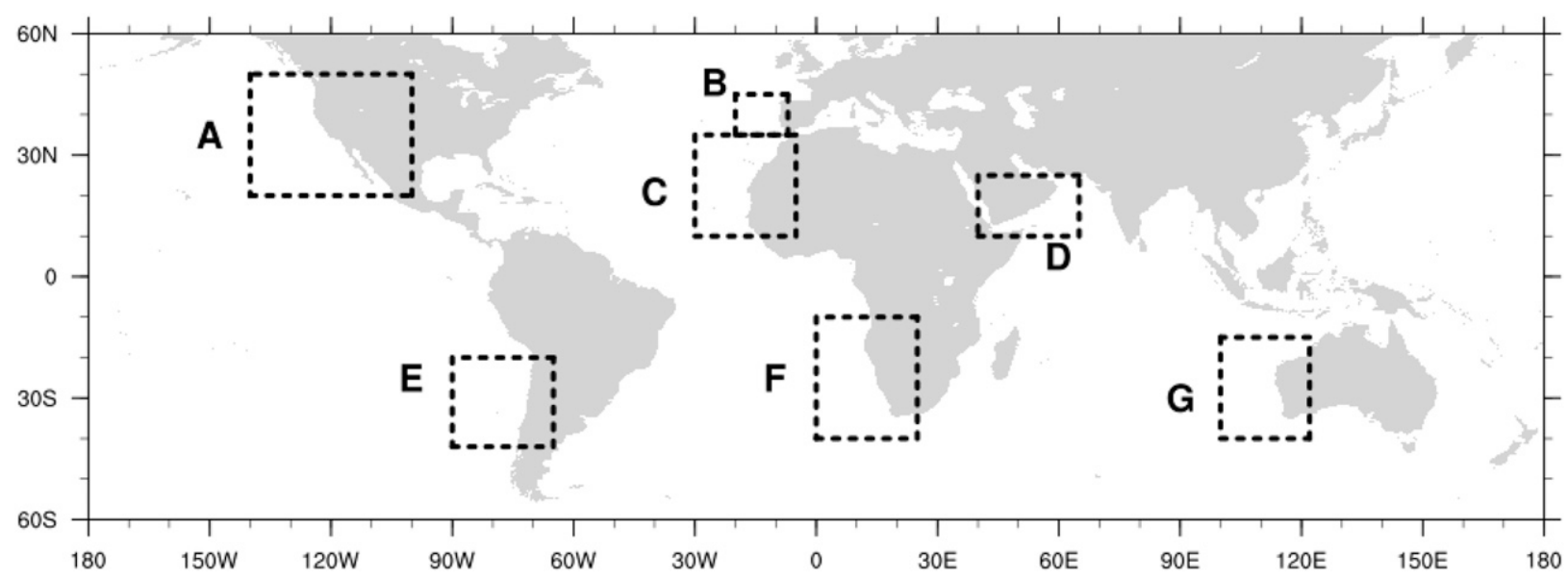

FIG. 1. Global map with regions where CLLJs occur enclosed in black: (a) CCJ, (b) IPCJ, (c) NACJ, (d) OCJ, (e) PCCJ, (f) BCJ, and (g) WACJ.

CLLJ frequency of occurrence and zonal PG for December-February (DJF), March-May (MAM), June-August (JJA), and September-November (SON) are shown in Fig. 2 and Fig. S1 (see supplemental material at the Journals Online website: http://dx.doi.org/ 10.1175/JCLI-D-17-0395.s1), respectively. The mean and maximum seasonal frequencies of occurrence for each of the reanalyses, for the respective CLLJ areas (see Fig. 1), can be seen in Table S1.

The spatial pattern of the CLLJ frequency of occurrence of the four reanalyses are in good agreement with Ranjha et al. (2013). However, some differences among reanalyses can be seen. The differences of the zonal PG between reanalyses are less perceptible when compared to the frequency of CLLJ occurrence. The mean global zonal PG, maximum in the CLLJs areas, except in Oman, is responsible for the coastal-parallel wind in the eastern boundary upwelling systems. This zonal gradient is more persistent in the summer in the $\mathrm{NH}$, and it is present during most of the year in the SH. The coastalparallel wind is intensified by the sharp thermal contrast between land and ocean.

In the $\mathrm{NH}$, the boreal summer season is the one in which the CLLJ frequencies of occurrence are higher in all reanalyses. During this season, coastal jet events in California, Iberian Peninsula, North Africa, and Oman are identified. The California CLLJ shows similar mean values of occurrence between ERA-Interim, JRA-55, and MERRA-2 (all around 15\%). The CFSR shows lower JJA mean frequency of occurrence of the California CLLJ (around 9\%). During boreal summer, the Iberian Peninsula CLLJ has similar values of mean frequency of occurrence in ERA-Interim, MERRA-2, and JRA-55. However, the CFSR does not represent this coastal jet well, since the mean frequency does not exceed 2\%. The Iberian Peninsula CLLJ climatology produced by Soares et al. (2014), with a higher-resolution downscaling hindcast, showed frequencies of occurrence around $35 \%$ along the west coast of Iberia in JJA, which is a higher value compared with the ones obtained here. This is related with the higher horizontal and vertical resolutions used in the regional hindcast $(9 \mathrm{~km}$ of horizontal resolution, with 49 vertical levels) and to the hourly output. Ranjha et al. (2016) showed the benefits of using higher horizontal resolution, which allows a more detailed representation of the coastal jets features; therefore, lower values of frequency of CLLJ occurrence are expected in coarser-resolution datasets. The North African CLLJ has an identical spatial pattern between all reanalyses in all seasons except in CFSR. These reanalyses show mean values of frequency of occurrence of the North Africa CLLJ above $10 \%$ in all seasons. Instead, CFSR has mean values below $10 \%$ except in JJA. For the Oman CLLJ, the CFSR and JRA-55 spatial pattern of frequency of occurrence is similar, with mean values around $19 \%$ for JJA. ERA-Interim and MERRA-2 show a higher CLLJ horizontal extent offshore compared to the other two, with mean frequency of occurrence around $27 \%$ and $25 \%$, respectively. These values of frequencies of CLLJ occurrence are lower compared with values above $70 \%$ found by Ranjha et al. (2015) from a simulation with a horizontal resolution of $6 \mathrm{~km}$.

In the $\mathrm{SH}$, the Peru-Chile CLLJ occurrences are found in two different regions: one located between $10^{\circ}$ and $20^{\circ} \mathrm{S}$ and other between $20^{\circ}$ and $40^{\circ} \mathrm{S}$. However, Ranjha et al. (2013) did not consider the first region as a CLLJ. Here, only the region between $20^{\circ}$ and $40^{\circ} \mathrm{S}$ will be analyzed as a CLLJ area [as in Garreaud and Muñoz (2005) and Ranjha et al. (2013)]. The spatial pattern of Peru-Chile CLLJ between ERA-Interim and MERRA-2 

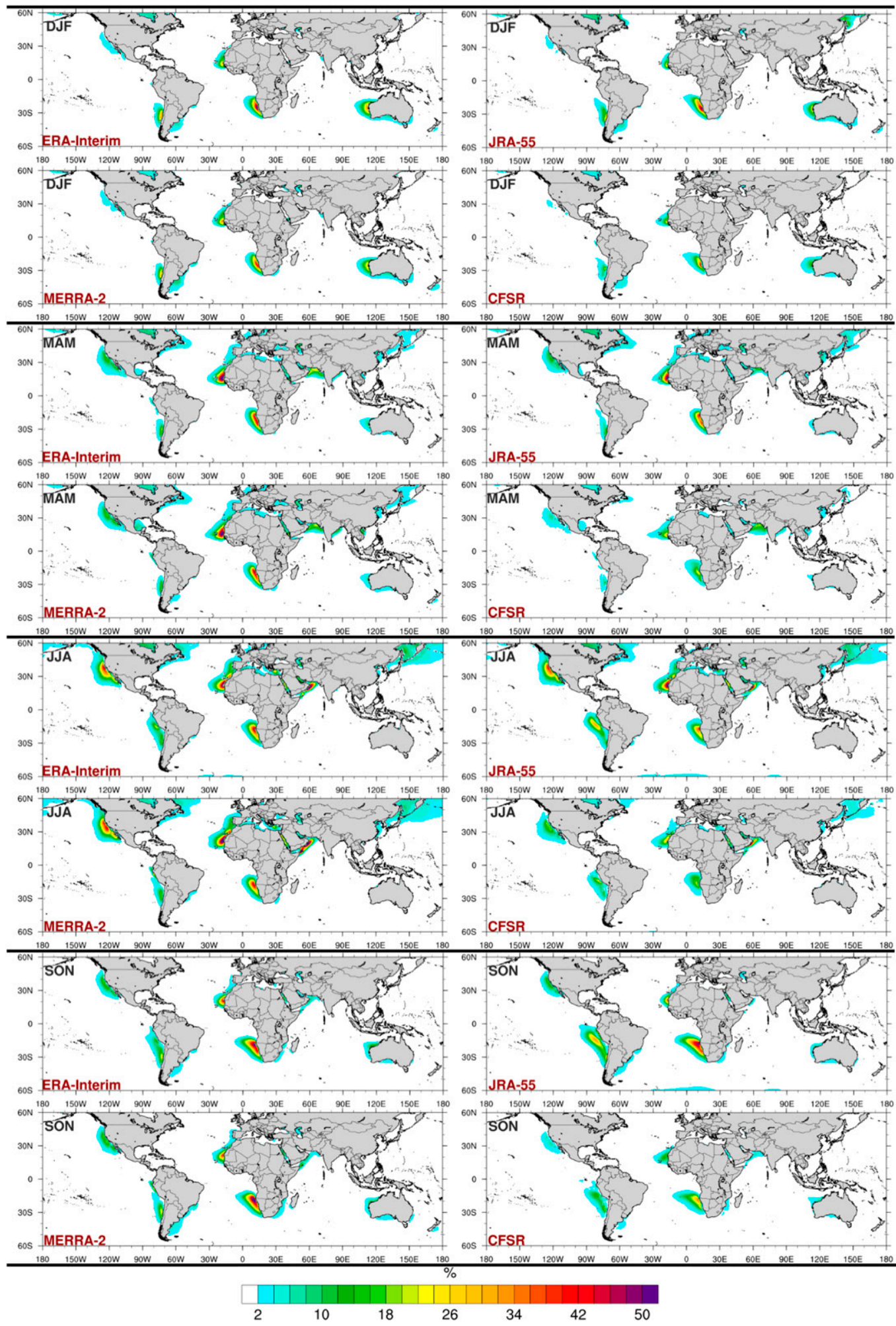

FIG. 2. Maps of seasonal CLLJ frequency of occurrence (percent) for ERA-Interim, JRA-55, MERRA-2, and CFSR, for (top to bottom) the DJF, MAM, JJA, and SON seasons. 
is similar for all seasons, with identical mean values of frequency of occurrence. The JRA-55 in DJF and MAM shows a spatial pattern identical to ERA-Interim and MERRA-2, however, with lower mean frequencies of occurrence. The Benguela CLLJ has a spatial pattern with mean values of frequency of occurrence similar between ERA-Interim, JRA-55, and MERRA-2 reanalyses. On the other hand, the CFSR reproduces well the location of the Benguela CLLJ but with lower CLLJ occurrences. Although the Benguela CLLJ has two maxima located in two different regions in different seasons (DJF and SON), the mean values of frequency of occurrence have small interseasonal differences. Patricola and Chang (2017) found these two maxima in these four reanalyses based in the annual mean of meridional wind at $10 \mathrm{~m}$. The pattern of the Western Australian CLLJ is also represented in the four reanalyses, although with differences in mean frequency of occurrence. In austral summer, this coastal jet has a mean value above $11 \%$ in all reanalyses except in CFSR, where it has a mean value around $7.5 \%$. In the intermediate seasons, the mean frequency of occurrence does not exceed the $8 \%$ in all reanalyses and is similar between them.

The frequency of CLLJ occurrence in ERA-Interim, JRA-55, and MERRA-2 are in good agreement with that obtained by Ranjha et al. (2013). However, the ERA-Interim data in this study have a horizontal resolution of $\sim 0.7^{\circ}$, which differs from the $1^{\circ}$ resolution used by Ranjha et al. (2013). This explains the slight increase in mean CLLJ frequency of occurrence. However, in the CFSR, despite representing the spatial pattern of the coastal jets across the seven areas, it does so with consistently lower values of frequency of occurrence compared to the three other reanalyses. In this study, ERA-Interim and JRA-55 have 60 vertical hybrid levels, and MERRA-2 has 72 vertical levels, whereas CFSR has only 37 pressure levels. In Fig. S2, the vertical levels of the four datasets are presented, where a zoom of the first kilometer is also shown, illustrating the different description of the MABL in these reanalyses (Fig. S2b). The lower frequency of occurrence in the CFSR reanalysis can be explained by its fewer vertical levels within the first kilometer of the atmosphere, inside the MABL. The CFSR dataset used here has only 4 levels within the lower $1000 \mathrm{~m}$ MSL, while ERA-Interim and JRA-55 have 10 levels and MERRA-2 has 7. The vertical discretization in the first kilometer of the atmosphere is very important in the filtering algorithm in order to define, with enough detail, the structure of the MABL. Although with different values of frequency of CLLJ occurrence than in regional studies, ERAInterim, JRA-55, and MERRA-2 reanalyses show good skill in representing the spatial pattern of coastal jets globally.

\section{Ensemble of coastal low-level jets}

Based on the comparison of the coastal low-level jet properties, two ensembles were built, the first including the four reanalyses and the second excluding CFSR. The difference in frequency of occurrence between the first and second ensemble is shown in Fig. S3 (see file JCLID-17-0395s1). Since CFSR has much lower frequencies of occurrence, explained by its poor vertical discretization, there is a significant loss of CLLJ occurrences in the areas of interest when comparing the first ensemble to the second. In some CLLJ areas, the dissimilarities range between $-2 \%$ and $-3 \%$, like in the California CLLJ in MAM and SON and in the Western Australian CLLJ in DJF. In JJA, in all CLLJ regions in the NH, the disparities are higher (between $-5 \%$ and $-8 \%$ ), with the exception of the Iberian Peninsula CLLJ, where the differences are lower (around -3\%). Along the CLLJ regions in $\mathrm{SH}$, the Benguela CLLJ differs between $-6 \%$ and $-8 \%$ in all seasons except in DJF, when the differences are lower, around $-3 \%$. For that matter, the ensemble used in the forthcoming sections is the one based on ERA-Interim, JRA-55, and MERRA-2 only (1980-2016 period).

\section{a. Annual/seasonal cycle of the coastal low-level jets}

The seasonal CLLJ frequency of occurrence and zonal PG, from the ensemble of three reanalyses, are shown in Figs. 3 and 4, respectively. The spatial mean and maximum seasonal frequency of occurrence for the four seasons are presented in Table 2. The annual cycle of coastal jets frequency of occurrence in the Northern and Southern Hemispheres are presented in Figs. 5 and 6, respectively. The ensemble mean is represented by the solid line, and the spread of reanalyses is depicted by the shading.

The seasonality of coastal jets differs between hemispheres, which is influenced by the seasonality of their synoptic forcings. The persistence of the subtropical high pressure systems is explained by the Hadley circulation, whose descending branches are associated with subsidence. The intensity of the subtropical high cells is inversely related to the intensity of the Hadley cell (Nguyen et al. 2013). During summer (winter) months, the Hadley cell is weaker (stronger), and the subtropical high pressure systems tend to be stronger (weaker) (Hoskins 1996). The variability of the Hadley cell is higher in NH. In Northern Hemisphere, during winter, the subtropical high cells are weak and have a more zonal extension, while in summer, they occupy almost all 

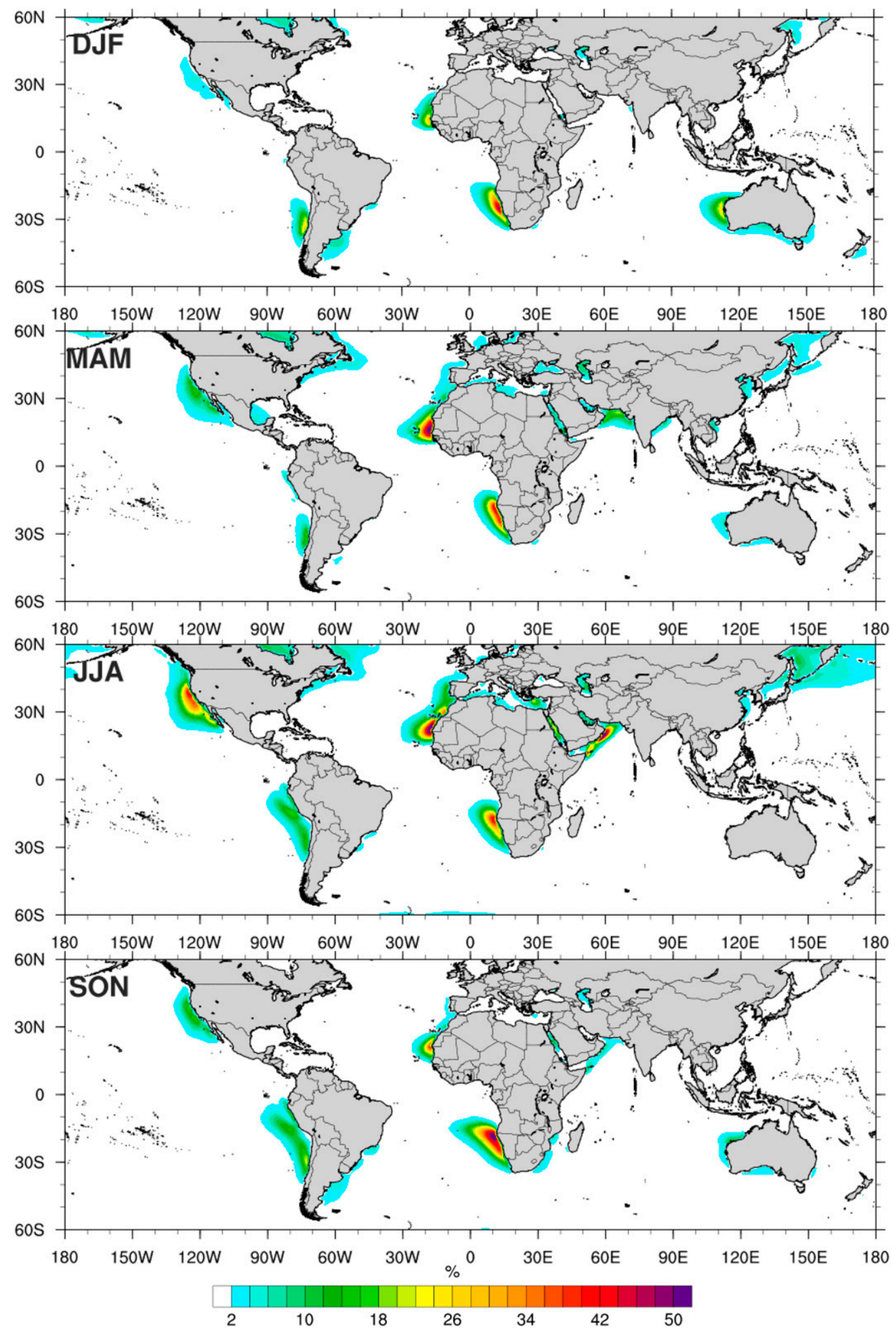

FIG. 3. Ensemble (ERA-Interim, JRA-55, and MERRA-2) global maps of CLLJ frequency of occurrence (percent) for (top to bottom) the four seasons. JRA-55 and MERRA-2 were interpolated for the ERA-Interim grid. 

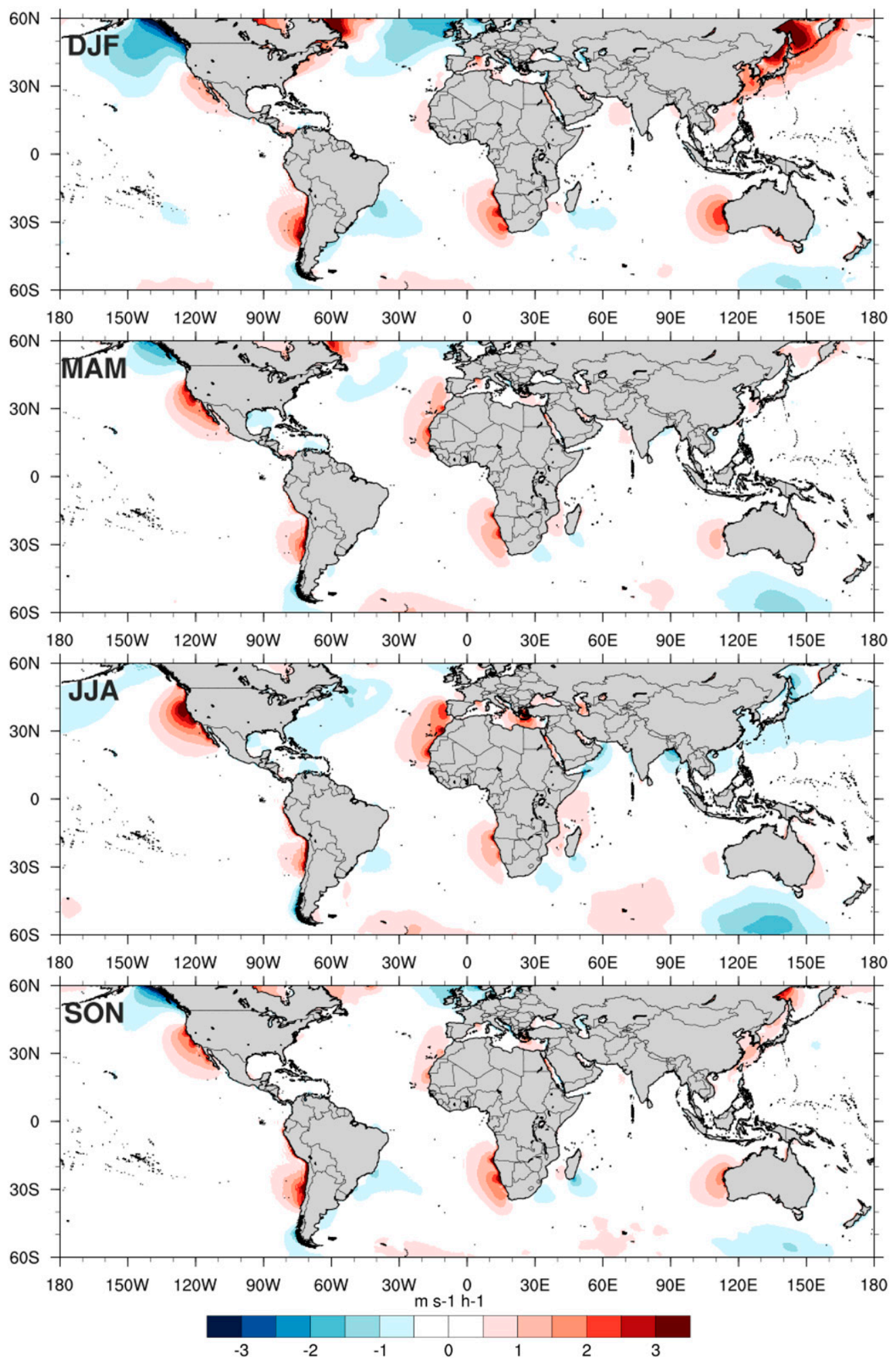

FIG. 4. As in Fig. 3, but for zonal pressure gradient $\left(\mathrm{m} \mathrm{s}^{-1} \mathrm{~h}^{-1}\right)$. 
TABLE 2. Summary of mean and maximum CLLJ frequency of occurrence for ensemble for all seasons for CCJ, IPCJ, NACJ, OCJ, PCCJ, BCJ, and WACJ.

\begin{tabular}{|c|c|c|c|c|c|c|c|c|}
\hline & \multicolumn{4}{|c|}{$\begin{array}{l}\text { Mean frequency occurrence } \\
(\%)\end{array}$} & \multicolumn{4}{|c|}{$\begin{array}{c}\text { Max frequency occurrence } \\
(\%)\end{array}$} \\
\hline & $\mathrm{DJF}$ & MAM & JJA & SON & DJF & MAM & JJA & SON \\
\hline & - & 00 & 15.74 & 8.59 & - & 6 & 4.17 & 16.6 \\
\hline I & - & 4.42 & 5 & 1.01 & - & 5.14 & 15.77 & 3.09 \\
\hline ACJ & 10.17 & 15.59 & 16.86 & 13.37 & 26.67 & 55.59 & 58.09 & 38.53 \\
\hline CJ & - & 10.69 & 25.65 & 5.75 & - & 23.03 & 61.18 & 8.66 \\
\hline PCCJ & 14.98 & 8.54 & 8.54 & 10.35 & 29.55 & 17.15 & 15.76 & 24.19 \\
\hline BCJ & 16.05 & 16.51 & 15.08 & 21.88 & 49.31 & 45.03 & 44.20 & 52.85 \\
\hline WACJ & 13.30 & 5.23 & - & 5.93 & 27.41 & 7.26 & - & 11.02 \\
\hline
\end{tabular}

of the NH oceans (Seager et al. 2003; Miyasaka and Nakamura 2005). The seasonality of the frequency of CLLJ occurrence is related with the seasonality of the zonal PG (Fig. 4). During boreal summer, the frequencies of occurrence of CLLJ in NH are higher than boreal winter (Fig. 3). In Southern Hemisphere, the subtropical high cells have some similarities, but there is a difference between the zonal SST asymmetry, which influences the seasonality of the high pressure systems over SH oceans (Seager et al. 2003). This zonal SST asymmetry is stronger in $\mathrm{SH}$ than in $\mathrm{NH}$; therefore, the seasonality of high pressure cells, and consequently of coastal jets frequency, is higher in $\mathrm{NH}$ than in SH. In each CLLJ region except the Oman CLLJ, the maximum frequency of occurrence occurs when the zonal PG is stronger and positive.

In the NH, CLLJ have higher frequencies of occurrence during boreal summer months (Figs. 3 and 5) except for the North African CLLJ (Fig. 5c), which has a maximum in May followed by the summer months. The lower CLLJ frequency of occurrence values in the $\mathrm{NH}$ during winter are explained by the weaker or inexistent zonal pressure gradient along the coast (Fig. 4). The North Pacific high and the thermal low over the North American Mojave Desert are responsible for the coastal-parallel flow along the

(b)

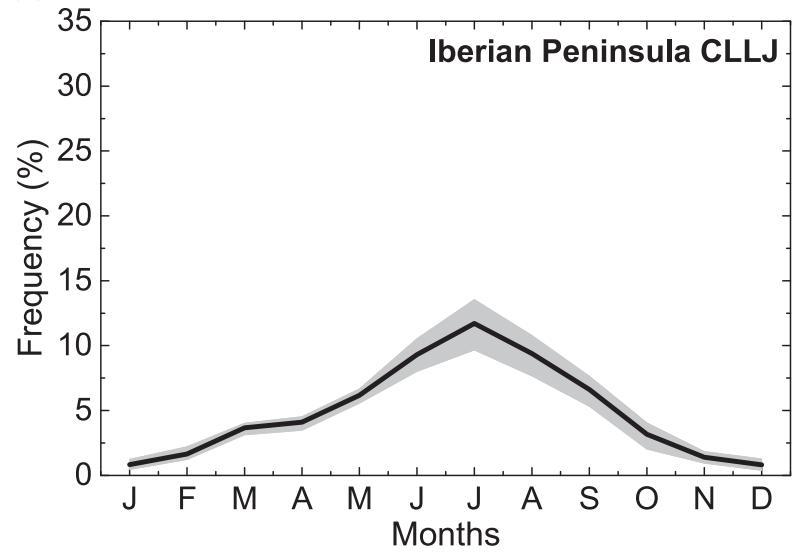

(d)

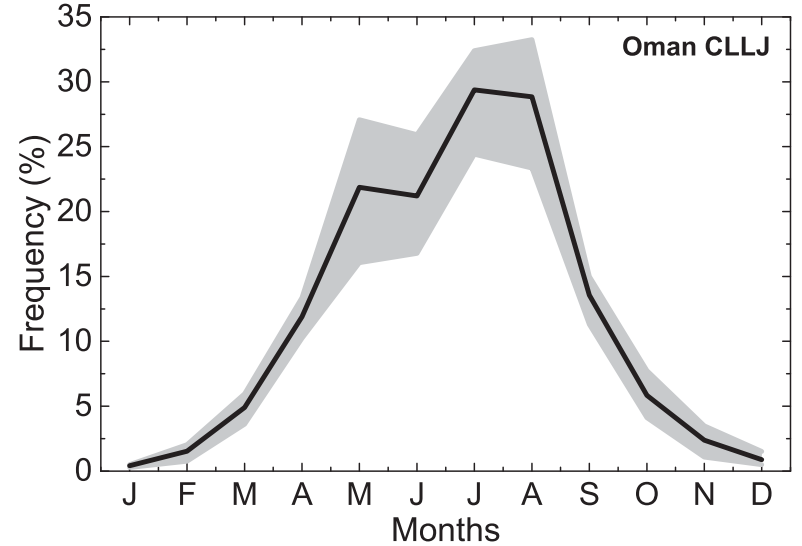

FIG. 5. Annual cycle of frequency of occurrence of CLLJ in NH: (a) California, (b) Iberian Peninsula, (c) North African, and (d) OCJs. The solid line represents the ensemble mean and the shading the spread of reanalyses used to build the ensemble. 
(a)

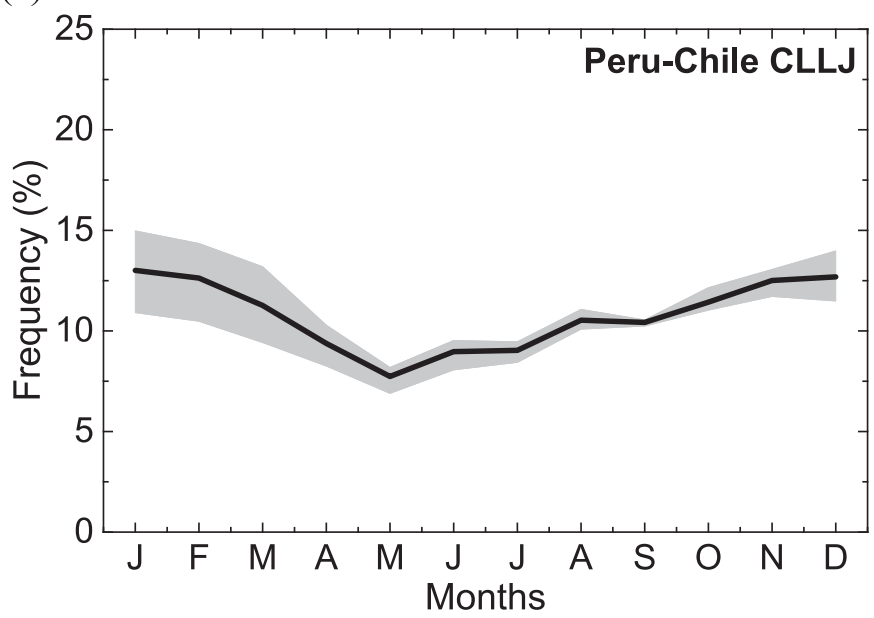

(b)

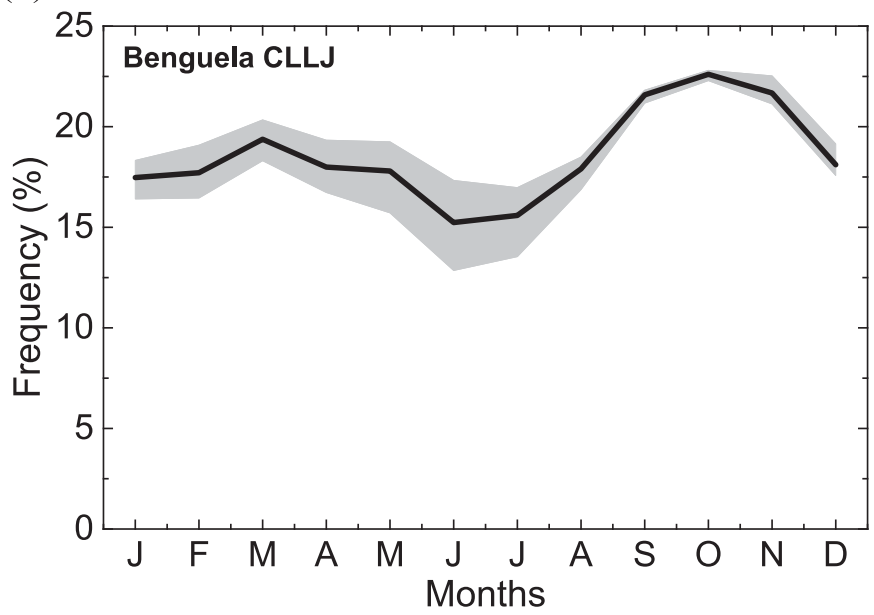

(c)



FIG. 6. Annual cycle of frequency of occurrence of CLLJ in SH: (a) Peru-Chile, (b) Benguela, and (c) WACJs. The solid line represents the ensemble mean and the shading the spread of reanalyses used to build the ensemble. 
California coast. The zonal PG intensifies in JJA with a value around $3 \mathrm{~m} \mathrm{~s}^{-1} \mathrm{~h}^{-1}$. During JJA, the California CLLJ has a mean (maximum) frequency of occurrence of about $14 \%(44 \%)$. In MAM and SON, the mean frequency occurrence is around $8 \%$, and the zonal $\mathrm{PG}$ has an identical pattern. The Iberian Peninsula and North African coastal jets are related to the presence of the Azores high pressure in the North Atlantic Ocean and with the development of a thermal low over land (Soares et al. 2014). This results in positive values of zonal PG along the Iberian Peninsula and North African coasts, in which maximum values occur during summer. In the west coast of the Iberian Peninsula, the maximum CLLJ frequency of occurrence does not exceed $20 \%$, and the mean is around $9 \%$ during JJA. The North African CLLJ is virtually present in all seasons although with less frequency of occurrence during boreal winter. In this season, this coastal jet is located more southward, between Cape Verde Islands and Senegal $\left(\sim 15^{\circ} \mathrm{N}\right)$, with a mean frequency of occurrence around $10 \%$ (Fig. $5 \mathrm{c}$ ). In MAM, this jet intensifies, and May is the month where the coastal jet actually is more frequent, with a mean value of about $24 \%$. The frequency of occurrence in JJA is similar to MAM, with a maximum of occurrences located more northward, between $20^{\circ}$ and $30^{\circ} \mathrm{N}$. From May to October, the North African CLLJ becomes gradually less frequent. The Oman CLLJ is not linked to a subtropical high and does not occur along an eastern boundary current (Ranjha et al. 2015). The high pressure system over the Indian Ocean and the thermal low over continental Asia results in a crossequatorial flow. The Findlater jet is a result of this wind pattern (Findlater 1969). During summer, the interaction between the Findlater jet and South Asia summer monsoon forces a coast-parallel southwesterly wind along the Oman coast (Ranjha et al. 2015). During boreal winter, the wind speed is northeasterly along the Oman coast, and consequently, the coastal jet is not detected. During JJA, the Oman CLLJ has a mean (maximum) frequency of occurrence of around $\sim 21 \%(\sim 61 \%)$. Although Ranjha et al. 2015 only studied one year, the values of frequency of occurrence obtained are similar to the values obtained for the ensemble mean. The Oman CLLJ is more frequent than the remaining two CLLJs in the $\mathrm{NH}$, with mean frequency of occurrence around $30 \%$ during July and August (Fig. 5d). In the intermediate seasons, the frequency of occurrence is lower although still rather high in May ( $\sim 22 \%$ similar to June).

In the SH, only the Western Australian CLLJ has a well-defined intra-annual variability, since the PeruChile and Benguela CLLJs occur virtually all year round. This is explained by the presence of the sharp zonal PG in these two regions with similar intensities along the year. The South Pacific high influences the west coast of subtropical South America, resulting in southerly winds along the coast (Garreaud and Muñoz 2005). The Peru-Chile CLLJ occurs in all seasons with some differences in frequency of occurrence. During austral summer, this coastal jet has a maximum frequency of around $23 \%$ and a mean occurrence of about $8 \%$. Although the zonal PG has identical mean intensity along the year, during SON and DJF, this term is maximum near the coast $\left(3 \mathrm{~m} \mathrm{~s}^{-1} \mathrm{~h}^{-1}\right)$. This explains why the Peru-Chile CLLJ becomes more persistent between November and February, reaching minimum frequency of occurrence mean values in winter months [in agreement with Garreaud and Muñoz (2005)]. The mean frequency of occurrence oscillates between $8 \%$ (May) and $13 \%$ (January).

The presence of the semipermanent Saint Helena high pressure system in the South Atlantic Ocean basin and of a thermal low pressure system inland, over the Namib Desert, provides the large-scale conditions to the development of the Benguela CLLJ (Nicholson 2010). When the South Atlantic subtropical high intensifies and is shifted toward the African continent, the Benguela CLLJ tends to be stronger (Patricola and Chang 2017). The pattern of zonal PG is very similar to that obtained by Patricola and Chang (2017). The Benguela CLLJ mean frequencies of occurrence are higher than $15 \%$ all year round, and this jet is characterized by two local maxima $\left(17.5^{\circ}\right.$ and $\left.25^{\circ} \mathrm{S}\right)$ in different seasons. These two local maxima of frequency of occurrence are related with the maximum of zonal $\mathrm{PG}$, around $3 \mathrm{~m} \mathrm{~s}^{-1} \mathrm{~h}^{-1}$, in these two points. During austral summer, the Benguela jet has a maximum frequency around $49 \%$, located at $25^{\circ} \mathrm{S}$. In MAM, this coastal jet extends along the whole coast of Namibia, and in DJF, the Benguela CLLJ is shifted equatorward, with the maximum value around $44 \%$ located at $17.5^{\circ} \mathrm{S}$. Although the Benguela CLLJ occurs along the whole year, it becomes more persistent between September and November (Fig. 6b), reaching its maximum in October (23\%). In austral spring, the Benguela coastal jet has a mean frequency around $20 \%$ and a maximum around $53 \%$. The Benguela CLLJ becomes more persistent between August and November and from January to March, with a maximum mean value in October and March, respectively. From May to July, when the land is coldest, this coastal jet reaches minimum frequencies of occurrences (Fig. 6b).

Unlike the remaining two coastal jets in the $\mathrm{SH}$, the Western Australian CLLJ has a high intra-annual 
(a)

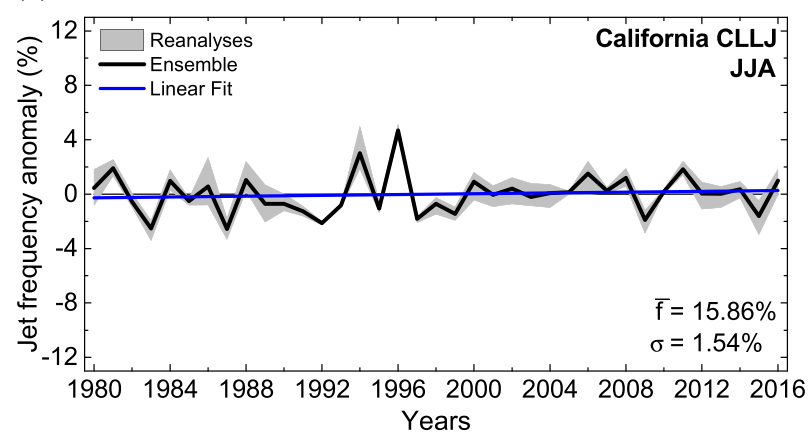

(c)

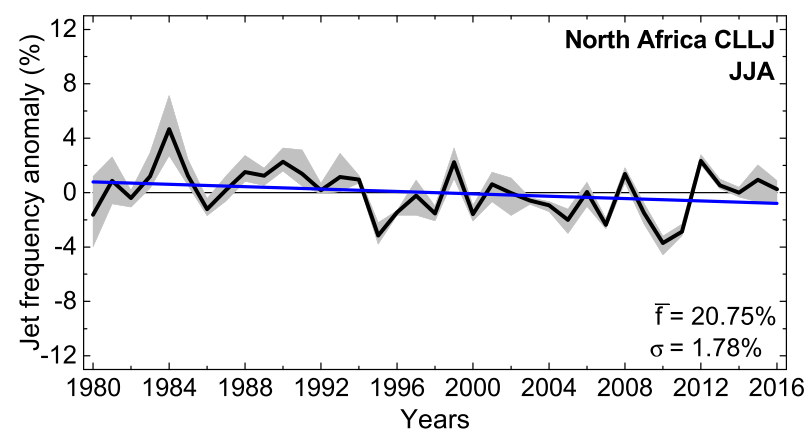

(b)

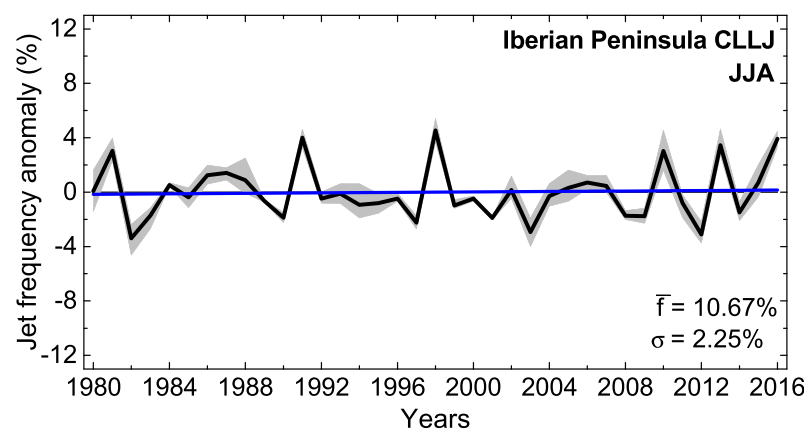

(d)

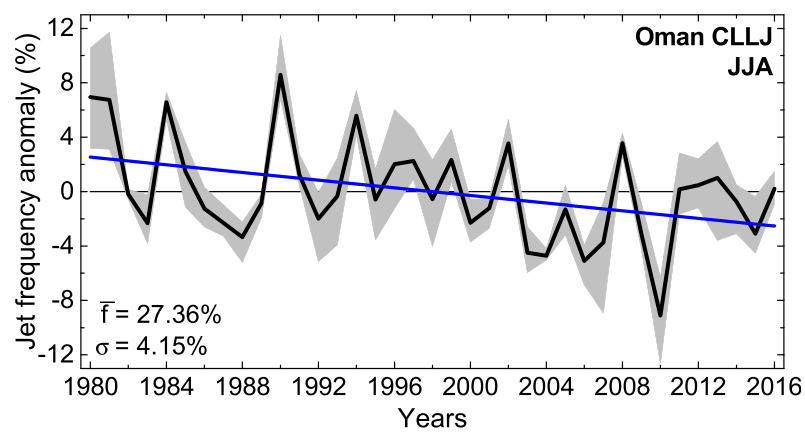

FIG. 7. Seasonal mean frequency of occurrence anomalies of CLLJ in NH: (a) California, (b) IPCJs for JJA, (c) NACJ for MJJ, and (d) OCJ for JJA. The solid line represents the ensemble mean and the shading the spread of reanalyses used to build the ensemble. The mean and standard deviation of the ensemble are also indicated in each plot. The blue line indicates the linear fit of the ensemble mean. Results are presented only for the season with higher frequency of occurrence in each region.

variability, occurring virtually only during summer. The coastal-parallel flow along the west coast of Australia during austral summer is a result of the interaction of the Mascarene high pressure system over the ocean and the thermal low over land. The zonal PG is maximum in DJF $\left(2 \mathrm{~m} \mathrm{~s}^{-1} \mathrm{~h}^{-1}\right)$, and during austral winter, there is no synoptic or local conditions for the coastal jet development. During austral summer, this coastal jet is more frequent, with a mean around $13 \%$ and a maximum of about $27 \%$. The Western Australian CLLJ was found also in the austral spring and autumn but with lower mean frequencies of occurrences $(\sim 5 \%)$, although in March, October, and November, the mean frequency of occurrence is above $5 \%$ (Fig. 6c).

\section{b. Interannual variability of CLLJ}

Aiming to analyze the interannual variability of the occurrence of each of the coastal jets, the anomaly relative to the seasonal mean frequency of occurrence has been computed for each CLLJ. Only the season presenting higher frequencies of occurrence is shown. These anomalies, along with each mean frequency of occurrence and standard deviation, are shown in Figs. 7 and 8 , for the $\mathrm{NH}$ and $\mathrm{SH}$ coastal jets, respectively. The linear tendencies from 1980 to 2016 for each coastal jet are also shown.

The variability of coastal jets is linked to the intermittence of its large-scale forcing and of the local processes. Differences in position and intensity of the high pressure cells over the ocean and in the inland surface radiative heating influences the flow along the coast and the land-sea thermal contrast and, consequently, the persistency of the coastal jet. Although present in all the coastal jets under study, the variability of frequency of occurrence differs between regions. The Oman CLLJ displays higher spread of frequency of occurrence with $\sim 4 \%$ standard deviation $(\sigma)$, where the anomalies oscillate between $\pm 8 \%$ (Fig. $7 \mathrm{~d}$ ). The Benguela CLLJ has a standard deviation around $3 \%$, with the anomalies of frequency of CLLJ fluctuating between $\pm 6 \%$ (Fig. $8 \mathrm{~b}$ ). The anomalies of frequency of occurrence of North African and Western Australian CLLJs vary between $\pm 4 \%$ in relation to the mean (Figs. $7 \mathrm{c}$ and $8 \mathrm{c}$, respectively) but with slightly different standard deviation. For California, North Africa, and Peru-Chile, this standard deviation does not exceed $2 \%$, while the Iberian Peninsula and Western Australian CLLJ is slightly above $2 \%$. The California, Iberian Peninsula, and Peru-Chile CLLJs have small variability to their 
(a)

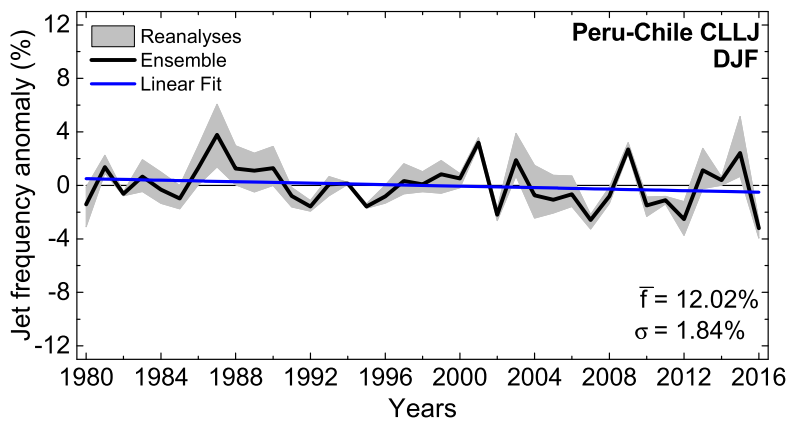

(b)



(c)

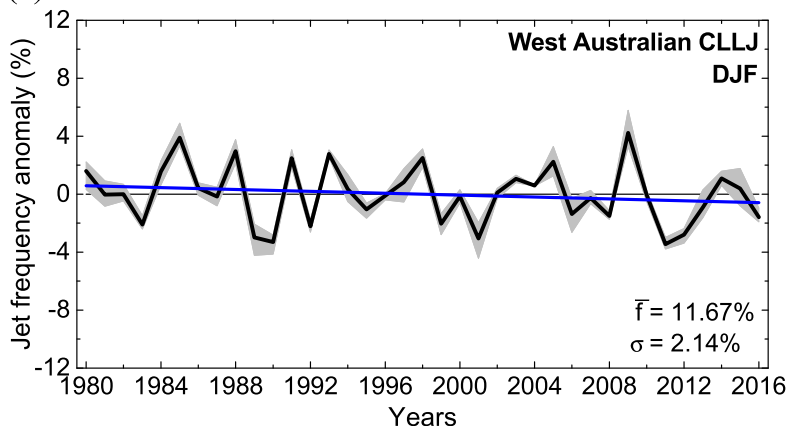

FIG. 8. As in Fig. 7, but for SH: (a) PCCJ for DJF, (b) BCJ for SON, and (c) WACJ for DJF.

respective mean frequency of occurrence compared to the remaining CLLJs, with a mean range, in most years, between $-2 \%$ and $2 \%$ (Figs. $7 \mathrm{a}, \mathrm{b}$ and $8 \mathrm{a}$, respectively). Some years, however, $+4 \%$ or $-4 \%$ variability with respect to the mean can occur. To analyze the linear tendency of frequency of CLLJ occurrence, the Student's $t$ test was applied. The linear trends of Benguela and Oman CLLJs for the 1980 to 2016 period are significantly different from zero at the 0.05 level. The Benguela CLLJ displays a positive linear trend, which indicates an increase in the frequency of occurrence of this coastal jet, but for Oman CLLJ, the linear trend is opposite. In the other CLLJs regions (California, Iberian Peninsula, North Africa, Peru-Chile, and Western Australia), there is no significant trend.

\section{c. Diurnal cycle of CLLJ frequency of occurrence}

Coastal jets mean frequency of occurrence display variations at seasonal and interannual scales but also have a diurnal cycle related to the diurnal heating contrast between land and ocean. The latter is due to the warming and cooling associated to the diurnal radiation cycle. According to Beardsley et al. (1987), during the night, the land-ocean temperature difference is lower, compared to daytime. For this reason, the capping inversion of the MABL along the coast rises, and the wind speed becomes weaker. In the morning, the sun rises and starts to heat the land, which leads to a change in the stable air to unstable. This destabilization allows the MABL air, which is offshore and below the inversion, to penetrate onshore. The slope of the inversion toward the coast increases, the wind speed increases within the MABL and becomes stronger, by late afternoon.

Figures 9 and 10 display, respectively, the Northern and Southern Hemispheres CLLJs diurnal cycle of the season with higher frequency of occurrence. It is important to have in mind that these global datasets have a 6 -h output rate $(0000,0600,1200$, and 1800 UTC). The diurnal cycle is identical between coastal jets, with a peak of occurrence around late afternoon to late evening and a minimum close to midday.

The Oman CLLJ has the most pronounced diurnal cycle of frequency of occurrence, with a difference between minimum and maximum near $12 \%$. This coastal jet displays lowest values of about $22 \%$ at 0600 UTC (1000 LT) and a maximum peak around 34\% at 1800 UTC (2200 LT; Fig. 9d). The diurnal dispersion of the Peru-Chile CLLJ is smaller ( $9 \%)$, with a maximum peak of about $19 \%$ at 0000 UTC (2100 LT) and a minimum of $\sim 10 \%$ at 1800 UTC (1500 LT). The diurnal cycle of frequency of occurrence of Benguela CLLJ varies between $18 \%$ and $26 \%$ at 1200 UTC (1500 LT) and 0000 UTC (0300 LT), respectively (Fig. 10b). Like the Benguela CLLJ, the Western Australian CLLJ has a difference between minimum and maximum around $8 \%$ (Fig. 10c). This coastal jet occurs the least at 0600 UTC (1400 LT). At 1200 UTC (2000 LT), the frequency of occurrence has a maximum peak of about $16 \%$, which is also identical to the value at 1800 UTC (0200 LT). The California CLLJ shows a maximum peak of frequency of occurrence of about 20\% at 0600 UTC (2300 LT) and a minimum value near $15 \%$ at 1800 UTC (1100 LT; Fig. 9a). The Iberian Peninsula and North African CLLJ present a similar diurnal cycle (Figs. 9b and 9c, respectively) although with different mean values; the lowest value takes place at 1200 UTC (and a peak maximum at 0000 UTC). The diurnal variation of 
(a)

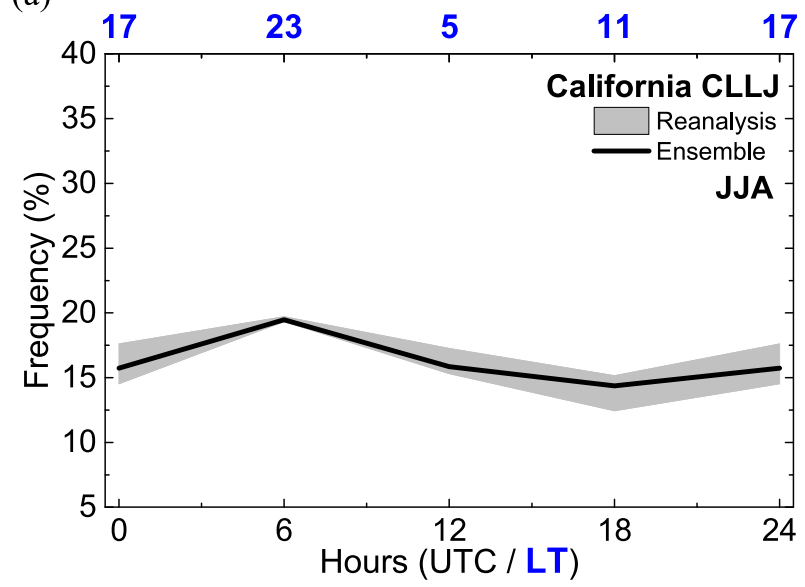

(c)

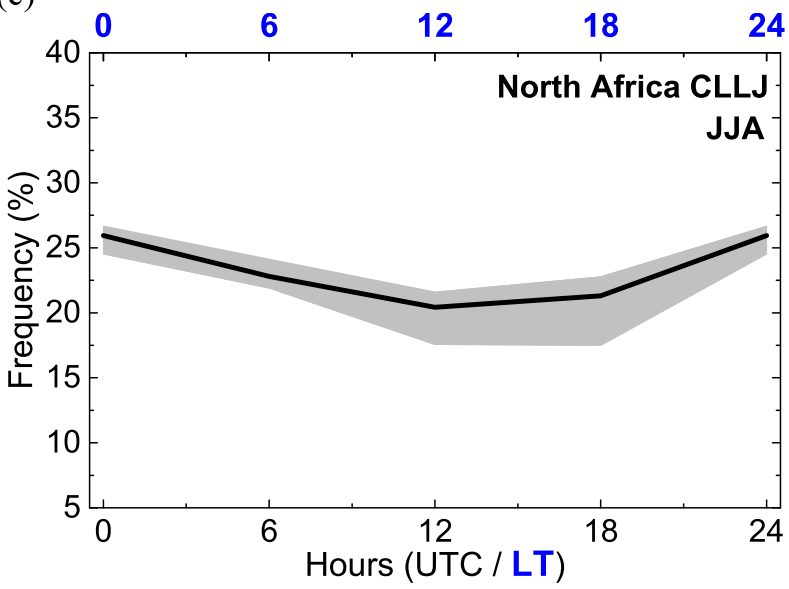

(b)

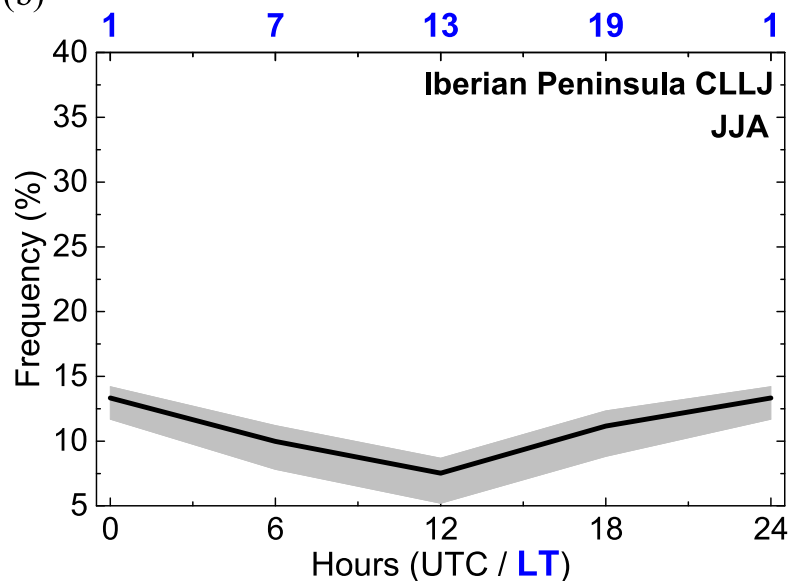

(d)

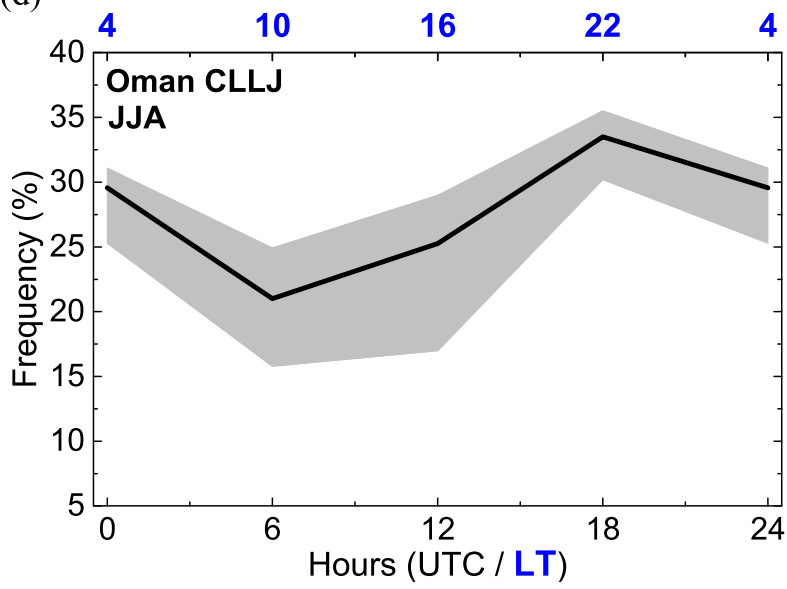

FIG. 9. Diurnal cycle of frequency of occurrence of CLLJ in NH: (a) California, (b) IPCJs for JJA, (c) NACJ for MJJ, and (d) OCJ for JJA. The solid line represents the ensemble mean and the shading the spread of reanalyses used to build the ensemble. Results are presented only for the season with higher frequency of occurrence in each region.

frequency of occurrence of the three abovementioned coastal jets is not very strong, since it only varies $\sim 5 \%$.

\section{d. Main properties of CLLJS}

The coastal jets are also characterized by their maximum wind speed (the jet maximum) and the jet height where these maxima occur. The histograms of the CLLJ jet wind speed maxima for the Northern and Southern Hemispheres coastal jets are show in Figs. 11 and 12, respectively. The box plots of the jet heights for all CLLJ regions is, on the other hand, displayed in Fig. 13, in this case only for the ensemble mean. Since the vertical levels of ERA-Interim, MERRA-2, and JRA-55 are not the same, the box plot of the jet height of the ensemble mean was built using all data of jet height together for the different coastal jets.

The distribution of jet wind speed for ERA-Interim shows a shift to lower wind speeds compared to the other two reanalyses, and that occurs in all CLLJ regions. The
JRA-55 and MERRA-2 display similar distributions, although the latter shows a slight shift to higher wind speeds. The Oman CLLJ is the most intense, with a mean jet wind speed value of about $20 \mathrm{~m} \mathrm{~s}^{-1}$ (Fig. 11d), followed by Benguela CLLJ with a mean value around $17 \mathrm{~m} \mathrm{~s}^{-1}$ (Fig. 12b). The mean intensity of the California and North African CLLJs is almost identical, $\sim 15 \mathrm{~m} \mathrm{~s}^{-1}$ (Figs. 11a,c), while the Iberian Peninsula, Peru-Chile, and Western Australia CLLJs are the weakest, with mean jet wind speeds around $13 \mathrm{~m} \mathrm{~s}^{-1}$ (Figs. 11b, 12a, and $12 \mathrm{c}$, respectively). The vertical location of the jet wind speed is also different between the coastal jets (Fig. 13). The Oman CLLJ is stronger than the others and also has a higher mean jet height, arising most of time between 420 and $570 \mathrm{~m}$ MSL; $90 \%$ of the jets in the other regions occur above $200 \mathrm{~m}$ MSL but have different height distributions. The mean jet height of the California and Western Australian CLLJ is around $400 \mathrm{~m}$, and $75 \%$ develop below $450 \mathrm{~m}$ MSL, while the 
(a)
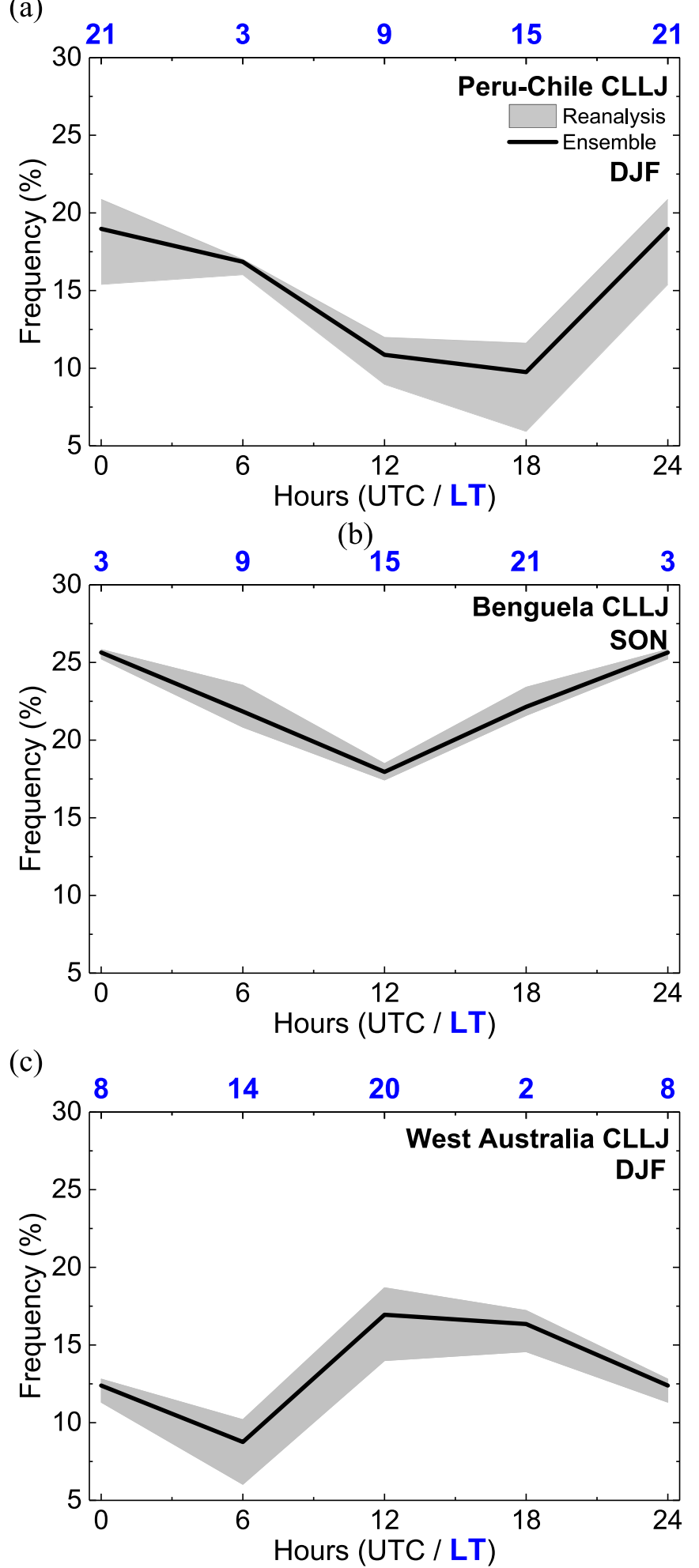

FIG. 10. As in Fig. 9, but for SH: (a) PCCJ for DJF, (b) BCJ for SON, and (c) WACJ for DJF. 
(a)

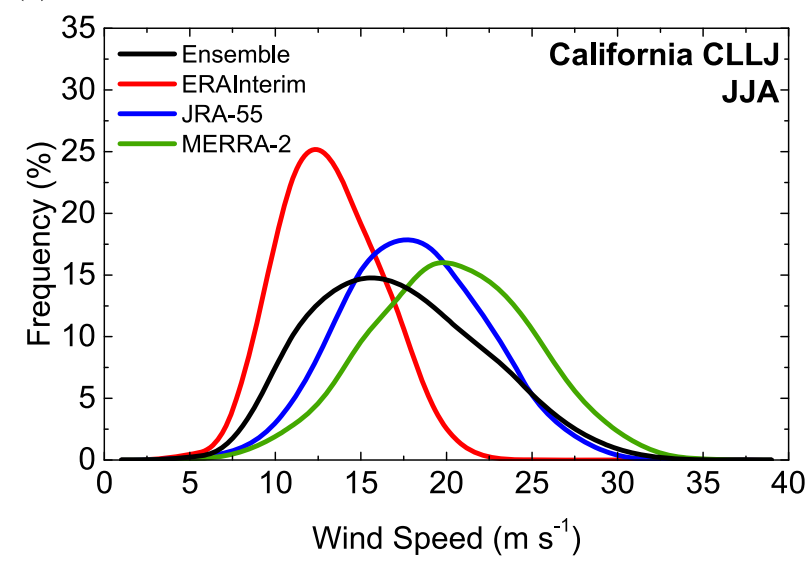

(c)



(b)

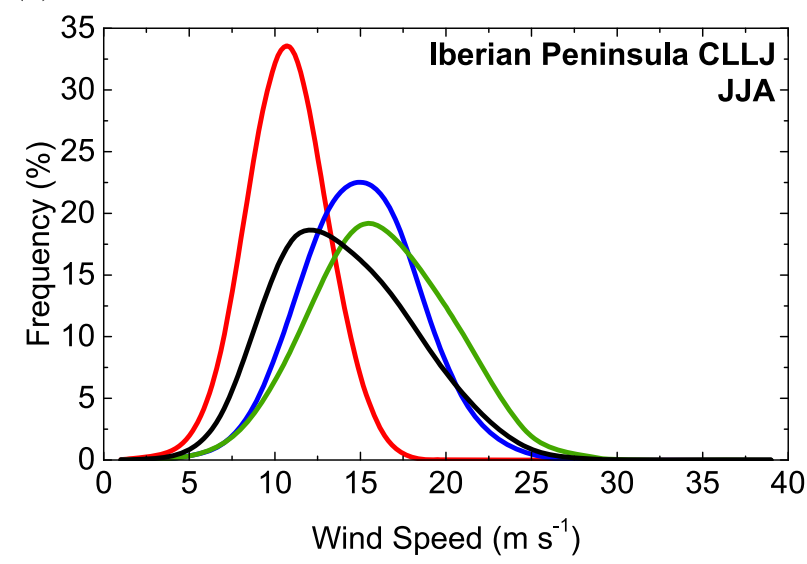

(d)

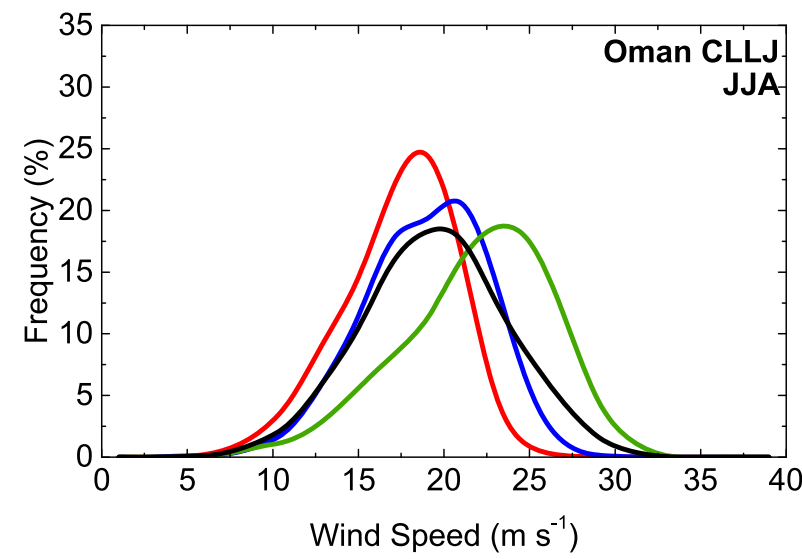

FIG. 11. Jet wind speed histograms of CLLJ in NH: (a) California, (b) IPCJs for JJA, (c) NACJ for MJJ, and (d) OCJ for JJA. The black line represents the ensemble mean, the red line represents the ERA-Interim, the blue line represents the JRA-55, and the green line represents the MERRA-2. Results are presented only for the season with higher frequency of occurrence in each region.

Peru-Chile and Benguela CLLJs occur most of the times below $550 \mathrm{~m}$ MSL. The Iberian Peninsula and North African CLLJs are found at lower altitudes, with $50 \%$ of jets between 300 and $400 \mathrm{~m}$ MSL.

\section{Conclusions}

In the present study, four global reanalyses (ERAInterim, JRA-55, MERRA-2, and CFSR) were used to understand their ability in representing the global coastal low-level jets and characterize their features for the 1980-2016 period. A detailed global climatology of coastal low-level jets was presented using an ensemble of reanalyses. This ensemble view offers a more robust understanding of CLLJs with less uncertainty than the use of only one reanalysis (Thorne and Vose 2010). The spatial and temporal variabilities of the frequency of occurrence and the features of each CLLJ were investigated, complementing the Ranjha et al. (2013) pioneer research. The global zonal pressure gradient was also computed for the four reanalyses and then for the ensemble.

To positively identify a CLLJ, the detection algorithm proposed by Ranjha et al. (2013) was used as a reference. This method was carefully revised, through sensitive tests, to diminish the detection of false positives. Several studies about CLLJ state that the jet wind speed maximum is found within or at the top of the MABL inversion layer. One of the criteria of the detection algorithm proposed by Ranjha et al. (2013) does not take into account if the coastal jet occurs at the top or at the level immediately below the MABL inversion. Therefore, the revised criteria here proposed includes the detection of the jet wind speed maximum within or at the top of the MABL inversion. The revised algorithm was applied to the four reanalyses temperature and wind speed data for the period of study.

At a global scale, it was shown that the highest zonal PG occur at the CLLJs areas, with the exception of the Oman CLLJ. The pronounced zonal pressure (and 
(a)

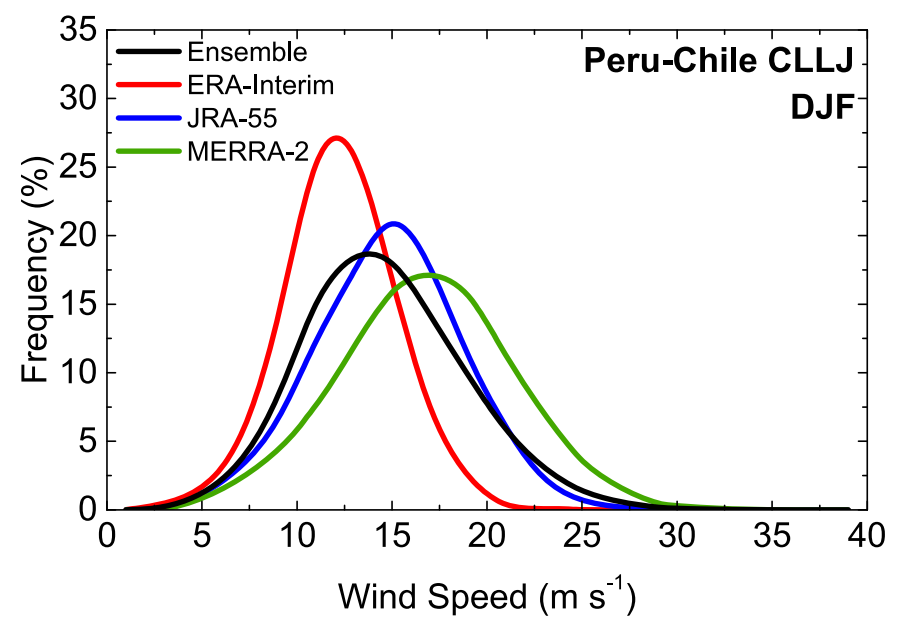

(b)

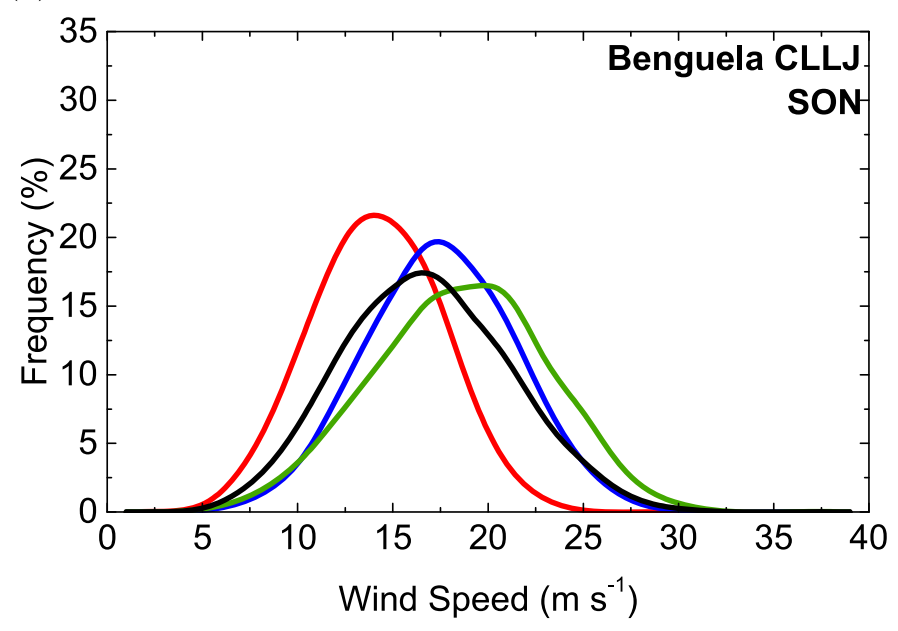

(c)



FIG. 12. As in Fig. 11, but for SH: (a) PCCJ for DJF, (b) BCJ for SON, and (c) WACJ for DJF. 


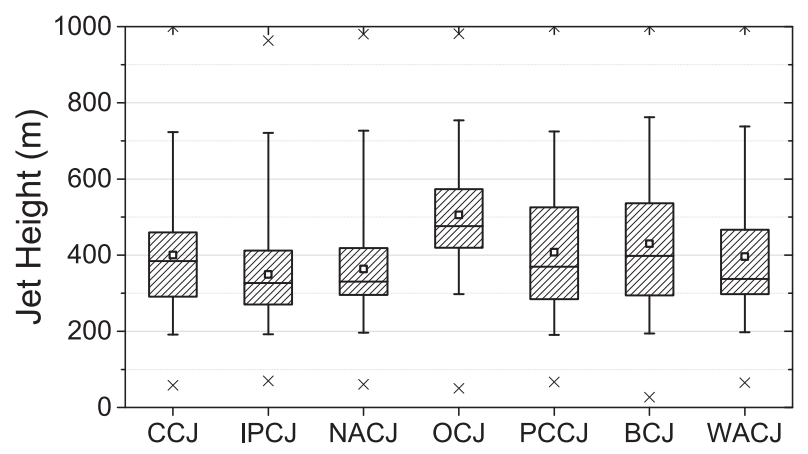

FIG. 13. Box plots of the jet height for the seven CLLJ areas: CCJ, IPCJ, NACJ, OCJ, PCCJ, BCJ, and WACJ. Individual boxes span from the 25 th to the 75 th percentiles, with the median represented by a straight line and the mean represented by a square and the absolute maximum and minimum indicated by $\times$ symbols. Results are presented only for the season with higher frequency of occurrence in each region.

thermal) gradient gives rise to an intensification of the coastal-parallel wind speed, which is favorable for the CLLJ occurrence, and defines in great measure its regional seasonal cycle. The spatial distribution of the CLLJ frequency of occurrence for the four reanalyses (Fig. 2) showed that the ERA-Interim, JRA-55, and MERRA-2 were in good agreement and were consistent with the previous climatology study. These three reanalyses displayed similar values of frequency of occurrence and alike spatial patterns along the seven CLLJ areas. In contrast, the NCEP CFSR exhibited lower values of CLLJ frequency of occurrence compared to the remaining reanalyses. This can be explained by its inferior number of vertical levels within the lower $1000 \mathrm{~m}$ MSL. Based on the assessment of the four reanalyses, an ensemble was built considering only ERA-Interim, JRA-55, and MERRA-2 for the 1980-2016 period. The seasonal spatial patterns of the JRA-55 and MERRA-2 were interpolated to the ERA-Interim grid.

The spatial variability of frequency of occurrence for the ensemble mean for all seasons showed a good representation of the climatology of global coastal low-level jets (Fig. 3), which emphasizes the importance of analyzing also the intermediate seasons. The seasonality of frequency of occurrence of CLLJ is stronger in NH than in $\mathrm{SH}$, which is closely linked to the analysis of the zonal PG. In NH, during the intermediate seasons, the CLLJ regions displayed lower frequency of occurrence except in the case of the North African CLLJ. The latter occurs all year round, but in DJF, the frequency is lower than in the remaining seasons. This coastal jet has a seasonal south-north shift, being located in DJF around $15^{\circ} \mathrm{N}$ and during JJA around $20^{\circ} \mathrm{N}$. The annual cycle of this coastal jet (Fig. 5c) revealed that in May, the mean frequency of occurrence is maximum. It was shown that the California,
Iberian Peninsula, and Oman CLLJs have higher mean values of frequency of occurrence in summer months, and that in winter, these coastal jets are almost nonexistent The Oman CLLJ is the coastal jet with higher values of frequency of occurrence in JJA, as previously shown by Ranjha et al. (2013, 2015), with maximum values above $60 \%$. In SH, the seasonal variability of the Benguela and Peru-Chile CLLJs is lower relative to other NH CLLJ regions and to the Western Australia CLLJ. The Peru-Chile and Benguela coastal jets occur during the whole year, with lower frequencies of occurrence in the austral winter. The Peru-Chile CLLJ was shown to be more persistent in DJF, while the Benguela CLLJ in SON. This Benguela CLLJ feature was not identified by Ranjha et al. (2013). Like the North Africa CLLJ, the Benguela CLLJ has two maximum peaks in different months (March and October). In DJF, the Benguela CLLJ is located at $17.5^{\circ} \mathrm{S}$, but during JJA, this coastal jet is shifted poleward, around $25^{\circ} \mathrm{S}$.

The interannual variability of anomalies of the frequency of occurrence for the ensemble was also analyzed. The interannual variability showed different results between CLLJs areas. The coastal area with higher variability was the Oman CLLJ, with a standard deviation $(\sigma)$ of the frequency of occurrence of around $4 \%$. The Benguela CLLJ also had a higher standard deviation but around $3 \%$. In the other regions, the standard deviation is around $2 \%$. Applying a statistical significance test to the linear tendency of frequency of CLLJ for the 1980 to 2016 period, only the Oman and Benguela CLLJs were significantly different from zero at the 0.05 level. The time series of anomalies of frequency of occurrence of Oman CLLJ showed a decrease in coastal jet occurrences, whereas the Benguela CLLJ displays an increase. A detailed analysis on these time series is needed in order to understand the factors behind these results.

The diurnal cycle of CLLJs is obviously related to the warming and cooling over land, which is associated to the diurnal radiation cycle. The maximum occurrence of CLLJs was detected around late afternoon and early evening and the minimum during daytime in all CLLJs. In all CLLJs areas, the histogram of the jet wind speed of ERA-Interim showed a shift to lower wind speed values in comparison to the other two reanalyses. The distribution of jet wind speed was similar between JRA-55 and MERRA-2, although the second reanalysis showed more strong events. The Oman CLLJ reveals more intense and higher coastal jet events than the others.

The present study showed a climatology of global coastal low-level jets using an ensemble of reanalyses. Nevertheless, there are some features related with the representation of CLLJs by reanalyses that need to be further understood. Moreover, an extensive analysis of 
the role of the different mechanisms on the interannual coastal jet variability will be pursued in a future study. Finally, the exploration of the impact of climate change on global coastal jets will be investigated in a future research using an ensemble of global climate models, which, despite the coarse resolution, will allow the characterization of the robustness and uncertainty of the projected changes.

Acknowledgments. Daniela Lima is supported by FCT through Doctoral Grant PD/BD/106008/2014, within the Earth Systems Doctoral Program of the Faculty of Sciences of the University of Lisbon. The work on this study was pursued in the framework of the SOLAR project (PTDC/GEO-MET/7078/2014), financed by the Portuguese Foundation for Science and Technology. All authors are part of the SOLAR project. This work was also supported by project FCT UID/GEO/50019/2013 - Instituto Dom Luiz. A special thanks to Miguel Nogueira for the discussions and advices given throughout this work.

\section{REFERENCES}

Beardsley, R. C., C. E. Dorman, C. A. Friehe, L. K. Rosenfield, and C. D. Wynant, 1987: Local atmospheric forcing during the Coastal Ocean Dynamics Experiment: 1. A description of the marine boundary layer and atmospheric conditions over a Northern California upwelling region. J. Geophys. Res., 92, 1467-1488, https://doi.org/10.1029/JC092iC02p01467.

Bengtsson, L., and Coauthors, 2007: The need for a dynamical climate reanalysis. Bull. Amer. Meteor. Soc., 88, 495-501, https://doi.org/10.1175/BAMS-88-4-495.

Bosilovich, M. G., J. Chen, F. R. Robertson, and R. F. Adler, 2008: Evaluation of global precipitation in reanalyses. J. Appl. Meteor. Climatol., 47, 2279-2299, https://doi.org/10.1175/ 2008JAMC1921.1.

— - and Coauthors, 2015: MERRA-2: Initial evaluation of the climate. NASA Tech. Rep. Series on Global Modeling and Data Assimilation NASA/TM-2015-104606/Vol. 43, 145 pp., https://gmao.gsfc.nasa.gov/pubs/docs/Bosilovich803.pdf.

Bridger, A. F. C., W. C. Brick, and P. F. Lester, 2005: The structure of the marine inversion layer off the central California coast: Mesoscale conditions. Mon. Wea. Rev., 121, 335-351, https://doi.org/ 10.1175/1520-0493(1993)121<0335:TSOTMI>2.0.CO;2.

Burk, S. D., and W. T. Thompson, 1996: The summertime low-level jet and marine boundary layer structure along the California coast. Mon. Wea. Rev., 124, 668-686, https://doi.org/10.1175/ 1520-0493(1996)124<0668:TSLLJA $>2.0$. CO;2.

Cardoso, R. M., P. M. M. Soares, D. C. A. Lima, and A. Semedo, 2016: The impact of climate change on the Iberian low-level wind jet: EUROCORDEX regional climate simulation. Tellus, 68A, 29005, https://doi.org/10.3402/tellusa.v68.29005.

Chao, S., 1985: Coastal jets in the lower atmosphere. J. Phys. Oceanogr., 15, 361-371, https://doi.org/10.1175/1520-0485(1985)015<0361: CJITLA $>2.0 . \mathrm{CO} ; 2$.

Courtier, P., J.-N. Thépaut, and A. Hollingsworth, 1994: A strategy for operational implementation of 4D-Var, using an incremental approach. Quart. J. Roy. Meteor. Soc., 120, 13671388, https://doi.org/10.1002/qj.49712051912.
Dee, D. P., and Coauthors, 2011: The ERA-Interim reanalysis: Configuration and performance of the data assimilation system. Quart. J. Roy. Meteor. Soc., 137, 553-597, https:// doi.org/10.1002/qj.828.

Donlon, C. J., M. Martin, J. Stark, J. Roberts-Jones, E. Fiedler, and W. Wimmer, 2012: The Operational Sea Surface Temperature and Sea Ice Analysis (OSTIA) system. Remote Sens. Environ., 116, 140-158, https://doi.org/10.1016/j.rse.2010.10.017.

Findlater, J., 1969: A major low-level air current near the Indian Ocean during the northern summer. Quart. J. Roy. Meteor. Soc., 95, 274-289, https://doi.org/10.1002/qj.49709540409.

Garreaud, R. D., and R. C. Muñoz, 2005: The low-level jet off the west coast of subtropical South America: Structure and variability. Mon. Wea. Rev., 133, 2246-2261, https://doi.org/ 10.1175/MWR2972.1.

Haack, T., S. D. Burk, and R. M. Hodur, 2005: U.S. West Coast surface heat fluxes, wind stress, and wind stress curl from a mesoscale model. Mon. Wea. Rev., 133, 3202-3216, https://doi.org/ 10.1175/MWR3025.1.

Hodges, K. I., R. W. Lee, and L. Bengtsson, 2011: A comparison of extratropical cyclones in recent reanalyses ERA-Interim, NASA MERRA, NCEP CFSR, and JRA-25. J. Climate, 24, 4888-4906, https://doi.org/10.1175/2011JCLI4097.1.

Hoskins, B. J., 1996: On the existence and strength of the summer subtropical anticyclones. Bull. Amer. Meteor. Soc., 77, 1287-1291.

Ishii, M., A. Shouji, S. Sugimoto, and T. Matsumoto, 2005: Objective analyses of sea-surface temperature and marine meteorological variables for the 20th century using ICOADS and the KOBE collection. Int. J. Climatol., 25, 865-879, https://doi.org/ 10.1002/joc.1169.

Janssen, P. A. E. M., 2004: The Interaction of Ocean Waves and Wind. Cambridge University Press, 300 pp.

Jones, P. W., 1999: First- and second-order conservative remapping schemes for grids in spherical coordinates. Mon. Wea. Rev., 127, 2204-2210, https://doi.org/10.1175/1520-0493(1999)127<2204: FASOCR $>2.0 . \mathrm{CO} ; 2$.

Kleist, D. T., D. F. Parrish, J. C. Derber, R. Treadon, W.-S. Wu, and S. Lord, 2009: Introduction of the GSI into the NCEP Global Data Assimilation System. Wea. Forecasting, 24, 1691-1705, https://doi.org/10.1175/2009WAF2222201.1.

Kobayashi, S., and Coauthors, 2015: The JRA-55 Reanalysis: General specifications and basic characteristics. J. Meteor. Soc. Japan, 93, 5-48, https://doi.org/10.2151/jmsj.2015-001.

Miyasaka, T., and H. Nakamura, 2005: Structure and formation mechanisms of the Northern Hemisphere summertime subtropical highs. J. Climate, 18, 5046-5065, https://doi.org/ 10.1175/JCLI3599.1.

Moalafhi, D. B., J. P. Evans, and A. Sharma, 2016: Evaluating global reanalysis datasets for provision of boundary conditions in regional climate modelling. Climate Dyn., 47, 2727-2745, https://doi.org/10.1007/s00382-016-2994-x.

Muñoz, R. C., and R. D. Garreaud, 2005: Dynamics of the low-level jet off the west coast of subtropical South America. Mon. Wea. Rev., 133, 3661-3677, https://doi.org/10.1175/MWR3074.1.

Nguyen, H., A. Evans, C. Lucas, I. Smith, and B. Timbal, 2013: The Hadley circulation in reanalyses: Climatology, variability, and change. J. Climate, 26, 3357-3376, https://doi.org/10.1175/ JCLI-D-12-00224.1.

Nicholson, S. E., 2010: A low-level jet along the Benguela coast, an integral part of the Benguela Current ecosystem. Climatic Change, 99, 613-624, https://doi.org/10.1007/s10584-009-9678-z.

Nuss, W. A., and Coauthors, 2000: Coastally trapped wind reversals: A new level of understanding from the experiment on 
coastally trapped disturbances. Bull. Amer. Meteor. Soc., 81, 719-743, https://doi.org/10.1175/1520-0477(2000)081<0719: CTWRPT $>2.3 . \mathrm{CO} ; 2$.

Overland, J. E., 1984: Scale analysis of marine winds in straits and along mountainous coasts. Mon. Wea. Rev., 112, 2530-2534, https:// doi.org/10.1175/1520-0493(1984)112<2530:SAOMWI >2.0.CO;2.

Parish, T. R., 2000: Forcing of the summertime low-level jet along the California coast. J. Appl. Meteor., 39, 2421-2433, https://doi.org/ 10.1175/1520-0450(2000)039<2421:FOTSLL > 2.0.CO;2.

Patricola, C. M., and P. Chang, 2017: Structure and dynamics of the Benguela low-level coastal jet. Climate Dyn., 49, 2765-2788, https://doi.org/10.1007/s00382-016-3479-7.

Pauly, D., and V. Christensen, 1995: Primary production required to sustain global fisheries. Nature, 374, 255-257, https://doi.org/ 10.1038/374255a0.

Ranjha, R., G. Svensson, M. Tjernström, and A. Semedo, 2013: Global distribution and seasonal variability of coastal lowlevel jets derived from ERA-Interim reanalysis. Tellus, $\mathbf{6 5 A}$, 20412, https://doi.org/10.3402/tellusa.v65i0.20412.

— , M. Tjernström, A. Semedo, G. Svensson, and R. M. Cardoso, 2015: Structure and variability of the Oman coastal low-level jet. Tellus, 67A, 25285, https://doi.org/10.3402/ tellusa.v67.25285.

, G. Svensson, and A. Semedo, 2016: Modeling coastal low-level wind-jets: Does horizontal resolution matter? $\mathrm{Me}$ teor. Atmos. Phys., 128, 263-278, https://doi.org/10.1007/ s00703-015-0413-1.

Reynolds, R. W., T. M. Smith, C. Liu, D. B. Chelton, K. S. Casey, and M. G. Schlax, 2007: Daily high-resolution-blended analyses for sea surface temperature. J. Climate, 20, 5473-5496, https://doi.org/10.1175/2007JCLI1824.1.

Rijo, N., A. Semedo, P. M. A. Miranda, D. C. A. Lima, R. M.Cardoso, and P. M. M. Soares, 2018: Spatial and temporal variability of the Iberian Peninsula coastal low-level jet. Int. J. Climatol., https://doi.org/10.1002/joc.5303, in press.

Saha, S., and Coauthors, 2010: The NCEP Climate Forecast System Reanalysis. Bull. Amer. Meteor. Soc., 91, 1015-1057, https:// doi.org/10.1175/2010BAMS3001.1.

Seager, R., R. Murtugudde, N. Naik, A. Clement, N. Gordon, and J. Miller, 2003: Air-sea interaction and the seasonal cycle of the subtropical anticyclones. J. Climate, 16, 1948-1966, https://doi.org/ 10.1175/1520-0442(2003)016<1948:AIATSC > 2.0.CO;2.

Semedo, A., P. M. M. Soares, D. C. A. Lima, R. M. Cardoso, M. Bernardino, and P. M. A. Miranda, 2016: The impact of climate change on the global coastal low-level wind jets: EC-EARTH simulations. Global Planet. Change, 137, 88-106, https://doi.org/10.1016/j.gloplacha.2015.12.012.

Soares, P. M. M., R. M. Cardoso, A. Semedo, M. J. Chinita, and R. Ranjha, 2014: Climatology of the Iberia coastal low-level wind jet: Weather Research Forecasting Model high-resolution results. Tellus, 66A, 22377, https://doi.org/10.3402/ tellusa.v66.22377.

_ D. C. A. Lima, R. M. Cardoso, and A. Semedo, 2017: High resolution projections for the western Iberian coastal low level jet in a changing climate. Climate Dyn., 49, 1547-1566, https:// doi.org/10.1007/s00382-016-3397-8.

Stensrud, D. J., 1996: Importance of low-level jets to climate: A review. J. Climate, 9, 1698-1711, https://doi.org/10.1175/ 1520-0442(1996)009<1698:IOLLJT>2.0.CO;2.

Sterl, A., 2004: On the (in)homogeneity of reanalysis products. J. Climate, 17, 3866-3873, https://doi.org/10.1175/ 1520-0442(2004)017<3866:OTIORP>2.0.CO;2.

Sydeman, W. J., M. García-Reyes, D. S. Schoeman, R. R. Rykaczewski, S. A. Thompson, B. A. Black, and S. J. Bograd, 2014: Climate change and wind intensification in coastal upwelling ecosystems. Science, 345, 77-80, https://doi.org/10.1126/ science.1251635.

Taylor, K. E., D. Williamson, and F. Zwiers, 2000: The sea surface temperature and sea ice concentration boundary conditions for AMIP II simulations. Lawrence Livermore National Laboratory PCMDI Rep. 60, 28 pp.

Thorne, P. W., and R. S. Vose, 2010: Reanalyses suitable for characterizing long-term trends. Bull. Amer. Meteor. Soc., 91, 353-361, https://doi.org/10.1175/2009BAMS2858.1.

Tjernström, M., 1999: Sensitivity of coastal atmospheric supercritical flow to ambient conditions. Tellus, 51, 880-901, https:// doi.org/10.3402/tellusa.v51i5.14499.

_ - and B. Grisogono, 2000: Simulations of supercritical flow around points and capes in the coastal atmosphere. J. Atmos. Sci., 57, 108-135, https://doi.org/10.1175/1520-0469(1995)052<0863: MTIOMS $>2.0$.CO;2.

Vallis, G. K., 2012: Climate and the Oceans. Princeton University Press, $244 \mathrm{pp}$.

Wang, D., T. C. Gouhier, B. A. Menge, and A. R. Ganguly, 2015: Intensification and spatial homogenization of coastal upwelling under climate change. Nature, 518, 390-394, https:// doi.org/10.1038/nature14235.

Warner, T. T., 2004: Desert Meteorology. Cambridge University Press, $595 \mathrm{pp}$.

Winant, C. D., C. E. Dorman, C. A. Friehe, and R. C. Beardsley, 1988: The marine layer off northern California: An example of supercritical channel flow. J. Atmos. Sci., 45, 3588-3605, https://doi.org/ 10.1175/1520-0469(1988)045<3588:TMLONC > 2.0.CO;2.

Wu, W.-S., R. J. Purser, and D. F. Parrish, 2002: Three-dimensional variational analysis with spatially inhomogeneous covariances. Mon. Wea. Rev., 130, 2905-2916, https://doi.org/ 10.1175/1520-0493(2002)130<2905:TDVAWS >2.0.CO;2.

Zhang, Q., H. Körnich, and K. Holmgren, 2013: How well do reanalyses represent the southern African precipitation? Climate Dyn., 40, 951-962, https://doi.org/10.1007/s00382-012-1423-z. 